\title{
Reduced heat transfer in saltwater by a magnetic field: Do oceans have a "geomagnetic brake"?
}

\author{
A.K.H. Pazur* \\ Ludwig Maximilians University, 13 Department Biology I, \\ 14 Menzinger Str. 67, D-80638 Munich, Germany
}

\begin{abstract}
Seawater is the major heat transporter in our global environment, covering more than two-thirds of the surface of the earth. With an average salinity of $\sim 3.5 \%$, it is a moderate electric conductor, which is permanently in motion by thermal and hydrodynamic forces. A magnetic field exerts a Lorentz force on seawater that principally influences both the dissipation of turbulence and the flow properties by magnetic friction. Here we show by experiments on laboratory scale, that convection in seawater is slowed down by an external static magnetic field and leads to a reduced heat flux resulting in a increased or decreased heat content in the volume in response to influx or drain of heat, respectively. Experimentally, the application of a vertical magnetic field of $60 \mathrm{mT}$ reduces the convective heat transport on the liquid-air surface within in 5 minutes by about $8 \%$ perpendicular to the field and up to $14 \%$ parallel to it. The effect is strongly correlated with the magnetic interaction parameter of the system, which relates the magnetic to the viscous volume force. In the natural environment the geomagnetic field is omnipresent. It is weaker by about three orders of magnitude compared with the magnetic field applied in the experiments. It has, however, an undisturbed and long-lasting impact on the convection, at low Reynolds numbers, in the large body of water in the deeper ocean below the mixed layer. There are no investigations regarding a possible contribution of this effect to natural saltwater flows, neither by proxy experiments nor by model calculations. The data presented raise the possibility that convective heat transport in the sea could be always slowed down by the geomagnetic field to a certain extent, besides it could be modulated by the geomagnetic secular variation on relatively short timescales like decades.
\end{abstract}

Keywords: Magnetic friction of salt water, Geomagnetic field, Oceanic heat transport

\section{Introduction}

Global heat balance is largely governed by the ability of the oceans to transport thermal energy from the equatorial region to higher latitudes. The waters are moved by winds on the surface and the thermohaline circulation down to large depths, which plays a decisive role in driving the earths oceanic "conveyor belt". This thermohaline circulation depends delicately on large scale gradients of temperature and salinity (Broecker 1992, Lund et al. 2006). Below the topmost layer of averagely $\leq 100 \mathrm{~m}$, which is well mixed, the ocean becomes "quiet". Small density gradients of the constituent waters drive a vertical transport of heat and water by about 1-2 cm/day; thus the complete turn-over about a depth difference of some $100 \mathrm{~m}$ may require a century and more (Carton et al. 2008).

Most studies of magnetic effects on seawater were focused on drag reduction in forced magnetohydrodynamic (MHD) flows (Hennoch and Stace 1995). The majority of related studies are simulations based on numerical approximations for either laminar, turbulent or vortex flows, based on the Stokes-Navier equation, that was previously extended by the Maxwell term (Kenjeres and Hanjalic 2000, Chaudhary and Sharma 2006, Kenjeres and Hanjalic 2004). Important findings include, a reduction of heat transfer in electrically conducting fluids in a

*Email: a.pazur@lrz.uni-muenchen.de 
magnetic field (MF) with direction anisotropy, by which the MF generates a Hartmann layer perpendicular to its direction (Kenjeres and Hanjalic 2004, Andreev et al. 2003). Further, for a mixed convection flow of seawater over a plate the speed and shear stress are reduced in a MF, while the local temperature and current density increase (Chaudhary and Sharma 2006). Changes of turbulent viscosity of seawater were also found under relatively weak MF of $<1 \mathrm{mT}$ using optical methods (Pazur and Winklhofer 2008). The theory also predicts damping of turbulence in the bulk flow of an electrically conducting liquid with low magnetic induction like, for example, seawater.

The aim of the present study was to quantify experimentally the reduction of heat transfer in seawater by a magnetic field (MF) and to consider the possible role of this effect caused by the geomagnetic field (Geo-MF) on the world's oceans. In a laboratory experiment the application of a vertical magnetic field of $60 \mathrm{mT}$ reduces significantly the convective heat transport observable in seawater over a distance of some centimetres that is measurable within minutes.

We summarise standard here standard notation for later reference:
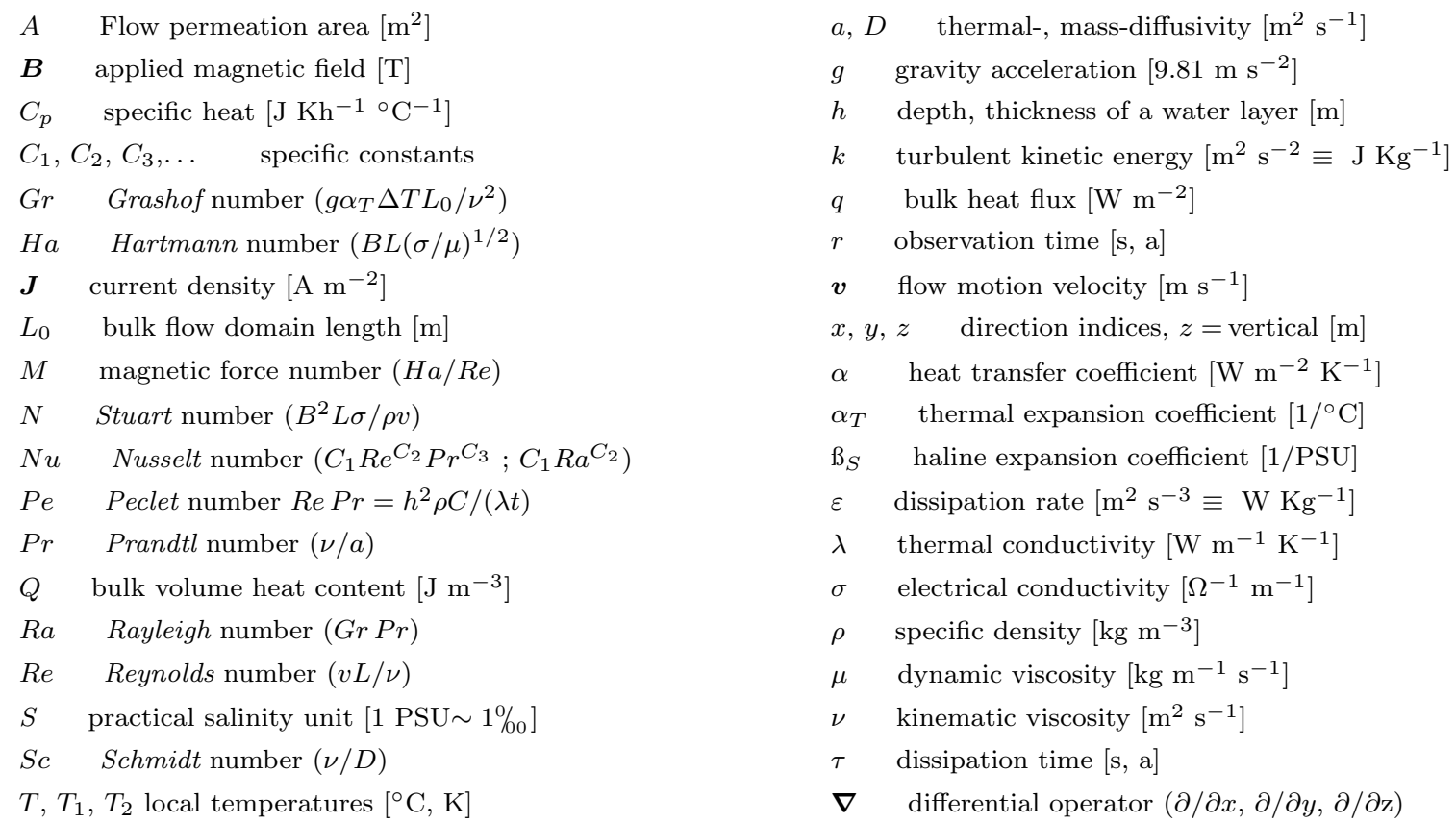

Table 1. Nomenclature and governing equations. For the calculation of $\rho, \sigma, \lambda, \mu, \nu$ and compound functions, established algorithms (Sharqawy et al. 2010 ) were used that account for the $T, S$ and $p$ dependence of seawater properties.

\section{General considerations}

In the most regions of the ocean the vertical transport process is dominated by the buoyancy flux $b_{f}$ (Karstensen and Lorbacher 2011), which can be expressed for a net surface heat flux $q_{\text {net }}$, evaporation $E$ and precipitation $P$ (each given in SI-units) by:

$$
b_{f}=\frac{g}{\rho_{\text {ref }}}\left(\frac{\alpha_{T}}{C} q_{\text {net }}+\rho_{\text {ref }} \beta_{S} S(E-P)\right) \text {, }
$$

where $S$ is the salinity expressed in PSU (practical salinity units, 1 PSU $=0.1 \%$ ), $C$ is the specific heat, $\alpha_{T}$ is the thermal and $\beta_{S}$ is the saline expansion coefficient, $\rho_{\text {ref }}$ is the reference density of freshwater and $g$ is the gravitational acceleration. The second important parameter 
in this context is the turbulent kinetic energy $k$ between two depths $h_{1}$ and $h_{0}$. which is given by the buoyancy anomaly:

$$
k=g \int_{h_{0}}^{h_{1}} \frac{\rho_{1}-\rho_{0}}{\rho_{\text {ref }}} \mathrm{d} h,
$$

where $\rho_{1}$ and $\rho_{0}$ are the densities at depth $h_{1}$ and $h_{0}$, respectively. Heat and salt concentration have opposite influences on the density $\rho$ and diffuse differently, which can lead to stratified turbulence (Sirevaag 2012, Stretch et al. 2010); thus, the largest scaling length is the thickness of the considered layer $\Delta h=\left|h_{1}-h_{0}\right|$. The largest time constant $\tau_{0}$ of mixing in vertical direction then will be $\tau_{0}=k / b_{f}$. Small local inhomogeneities in the body of water like "salt fingers" ( size 1-20 cm) can persist in the deep sea for days and give evidence of such slow mixing processes (St Laurent and Schmitt 1999). Generally, the relation of advective to diffusive heat transport through $\Delta h$ can be described by the Peclet number $P e=R e P r$ :

$$
P e=\frac{\Delta h|\boldsymbol{v}|}{a}=\frac{\Delta h|\boldsymbol{v}| \rho C}{\lambda}=\frac{(\Delta h)^{2} \rho C}{\lambda \tau_{0}},
$$

where $a$ is the thermal diffusivity, $C$ is the specific heat and $\lambda$ is thermal conductivity, see also table 1): In the third (right-hand) expression, for the velocity $\boldsymbol{v}$ we have substituted the ratio of the characteristic length of the system length (here $\Delta h$ ) to the thermal equilibration (turn over) time $\tau_{0}$.

A magnetic field (MF) exerts additional forces on charged particles, hampering their motion. It does so in electrically conducting fluids like seawater. The chemical composition of ions in seawater is nearly constant worldwide following Marcet's principle (Janz and Singer 1975). Due to the ions present in seawater, an MF will influence mixing processes in it. Seawater with an average salt concentration of 35 PSU has a electric conductivity of $\sigma \sim 4.79 \Omega^{-1} \mathrm{~m}^{-1}$ at $20^{\circ} \mathrm{C}$, corresponding to a cumulative ion strength of $\sim 0.69 \mathrm{~mol} / \mathrm{L}$ and is widely organised in the hydration shells with a radius of $\sim 1 \mathrm{~nm}$ that are dragged along by the ions.

An MF deflects the ions (including the attached water) by the Lorentz force onto curved paths in a plane perpendicular to its direction, but without any acceleration, which slows down their translational motion. This effect depends on heat- and salt-concentration, consequently additional frictional forces occur in small local gradients of heat and salinity in the presence of an MF. This attenuates flow turbulence (De Luca 2009) and slower temperature equalisation should be observable in a distinct volume after applying an MF. The Lorentz force $\boldsymbol{f}_{L}\left[\mathrm{~N} / \mathrm{m}^{3}\right]$ acting on a unit volume of charges moving with the average velocity $\boldsymbol{v}$ is

$$
\boldsymbol{f}_{L}=\boldsymbol{B} \times \boldsymbol{j}=\sigma\left(-\nabla \varphi_{e}+\boldsymbol{v} \times \boldsymbol{B}\right) \times \boldsymbol{B},
$$

where $\boldsymbol{B}$ is the magnetic flux, $\boldsymbol{j}$ is the electric bulk current density $\left[\mathrm{A} / \mathrm{m}^{2}\right]$ and $\boldsymbol{\nabla} \varphi_{e}$ is the electric field $[\mathrm{V} / \mathrm{m}]$ of small scale fluctuations down to the smallest scale of turbulent energy dissipation (Kolmogorov length). In contrast to other volume forces, like gravitational buoyancy, the Lorentz force is always dissipative (Kenjeres and Hanjalic 2000); thus, it is able to build self-assembling structures like concentration fields in fluids with mobile charge carriers (Hanjalic and Kenjeres 2002, Nadoor and Bhattacharyya 1981). Consequently the MF never contributes energy to any turbulent flux in the system, but merely causes a more or less creeping redistribution of the contained heat and momentum.

The contribution of the Lorentz force can be related by the magnetic force number $M$, and the effect by an MF on the accumulation of heat in a given volume can be determined directly by the magnetic interaction parameter $N$ (Stuart number), which both relate the electromagnetic and viscous forces to the Hartmann and Reynolds numbers $(H a, R e)$ of the fluid (Shimomura 1991):

$$
M=\frac{H a}{R e}, \quad N=\frac{H a^{2}}{R e}=\frac{H a^{2} P r}{P e} .
$$


For a flow along a length $l$ with speed $v=|\boldsymbol{v}|$, magnetic flux $B=|\boldsymbol{B}|, H a$ is defined (for $P e$ see $(3))$ as

$$
H a=B l \sqrt{\frac{\sigma(T, S, p)}{\mu(T, S, p)}}
$$

For free convection $R e$ can be expressed by the Grashof number $G r$, and respectively the Rayleigh number $R a=G r P r$, as

$$
R e=\frac{\rho(T, S, p) v l}{\mu(T, S, p)}=\sqrt{0.4 G r}=\sqrt{\frac{0.4 R a}{P r}},
$$

where $\sigma, \rho$ and the dynamic viscosity $\mu$ depend on temperature $T$, salinity $S$ and pressure (depth) $p$. The vertical heat flux $q_{z}$ in or out of a volume with the random speed of water movement $v$ inside will then be diminished to $q_{z}^{\prime}$ by the vertical magnetic component $B_{z}$ :

$$
q_{z}^{\prime}=q_{z}\left(1-\frac{B_{z} \sqrt{\sigma \mu}}{\rho \nu}\right) .
$$

In a closed system with no regeneration of turbulent kinetic energy, any convective and advective flow would completely vanish after a magnetic breaking time

$$
t_{m}=\frac{\rho}{\sigma B^{2}},
$$

as proposed by Ji and Gardner (1997). For a steady state system, where an equilibrium between the in- and out-flow of heat and momentum exists, the magnetic interaction parameter $N$ can then also be expressed by the ratio of $\tau_{0}$ and $t_{m}$ :

$$
N=\frac{B^{2} l \sigma}{v \rho}=\frac{B^{2} \sigma}{\rho} \tau_{0}=\frac{\tau_{0}}{t_{m}} .
$$

\section{Material and methods}

Artificial seawater, and $\mathrm{NaCl}$ solutions with different salt concentrations $(1-10 \% \mathrm{w} / \mathrm{w})$, were used both for the experiments and for the calibration of heat fluxes and electrical conductivity. Stock solutions of artificial seawater were prepared using ultra pure water (resistance $>18 \mathrm{M} \Omega / \mathrm{cm}$ ) and a commercial sea salt mixture (BioMarine Erkrath, pro-analysi quality) at room temperature $\left(\sim 20^{\circ} \mathrm{C}\right)$. The main experiments were performed with seawater conforming to an established standard salinity of $35 \pm 0.2$ PSU, pH 8.1 \pm 0.05 (Janz and Singer 1975). For $\mathrm{NaCl}$ solutions (1-10\% w/w), ultra pure water and $\mathrm{NaCl}$ (Fluka p.a., 71382) were used. All salts were completely dissolved by warming to $\sim 30^{\circ} \mathrm{C}$ and stirring for $20 \mathrm{~min}$., and then rested for at least $24 \mathrm{hr}$. to ensure absence of precipitates. The electric conductivity of all used electrolytes was determined by a conductivity meter (Type CDM 3, Hillerkus). Before performing experiments, samples were degassed for $1 \mathrm{hr}$. and subsequently rested for $1 \mathrm{hr}$. in the flow cell for gas and temperature equilibration; gas exchange in sea- and saltwater is slower than in freshwater (Gat and Shatkay 1991). Distilled water was used as reference and $\mathrm{NaCl}$ solutions for thermal calibration. The experiments were performed in a horizontal, circular flow cell with a diameter of $95 \mathrm{~mm}$ (figure 1), which provided the lateral reference heat contact by a copper enclosure that was generally maintained at a reference temperature $T=8 \pm 0.035^{\circ} \mathrm{C}$ $(281.15 \mathrm{~K})$ by a water thermostat. A sample (bath) volume of $30 \mathrm{ml}$ was used for all experiments and the surface was in contact with the air. Two custom-built small piston pumps and a small stirring motor (Maxon $\AA$ F2130) with a custom built rotor provided an efficient temperature equilibration in the water and the air above, respectively, before an experiment was started (figure 1). This forced mixing was stopped $300 \mathrm{~s}$ before the experiment began in 


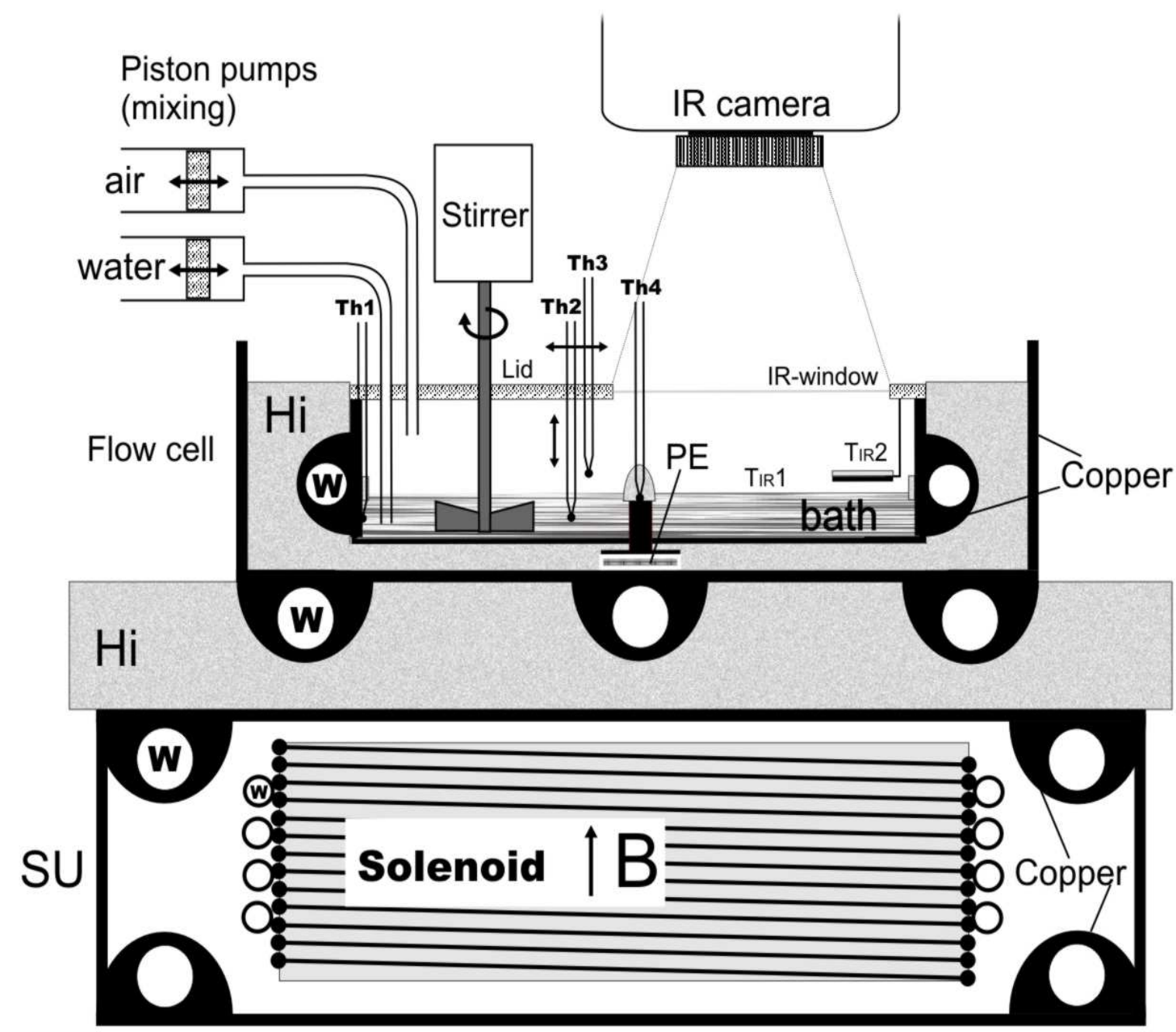

Figure 1. Schematic of the experimental apparatus (not drawn to scale, for functional description see text). The apparatus consisted of two subunits, a horizontal, circular flow cell (top) with a diameter of $97 \mathrm{~mm}$ containing the seawater bath, and the solenoid unit (SU, below) with the solenoid generating a vertical magnetic field $B$. Both were electrically shielded and allowed independent temperature control by copper housings with inserted water channels (W). The programmable heating was done by a Peltier element in the centre (PE). The temperature profile was monitored at by thermocouples (Th 1-4) in the water and the air above. The position of the two inner ones (Th2, Th3) could be varied by several suited perforations in the lid. The IR-camera allowed thermo-imaging of a $180^{\circ}$ segment of the water surface $\left(T_{I R} 1\right)$ and the air above as a reference $\left(T_{I R} 2\right)$. A stirrer and two little piston pumps allowed temperature equilibration in the entire bath and the air above before experiments were started.

order to arrest forced air- and water-flows. Four thermocouples (RS Components $\AA$, Type K, $\mathrm{NiCr}-\mathrm{Ni}$ ) were used for temperature monitoring of the bath and the air above. Two of them (Th1, Th4) where used for monitoring the reference temperatures, the other (Th2, Th3) could be optionally placed at different locations for recording local temperature profiles. The sensitivity was $0.0260^{\circ} \mathrm{C} /$ digit on a custom-built data recorder, which provided 4 channels and was controlled by an Intel-Pentium PC. Each channel delivered 1024 single temperature readings per second, which were then integrated to one second means and the resulting nominal confidence interval was $\sim 0.001^{\circ} \mathrm{C}$. Customised software was used for computer control of all units and for data acquisition. Numerical evaluations were performed with MS-Excel $\AA$ and Sigma Plot ( together with self-written programs for Fast Fourier Analysis (FFT). Additionally about $50 \%$ of the water surface could be simultaneously recorded by an IR-camera (Trotec $\AA$ ) IC-series) through a thin film of polyethylene permitting sufficient optical transmission down 


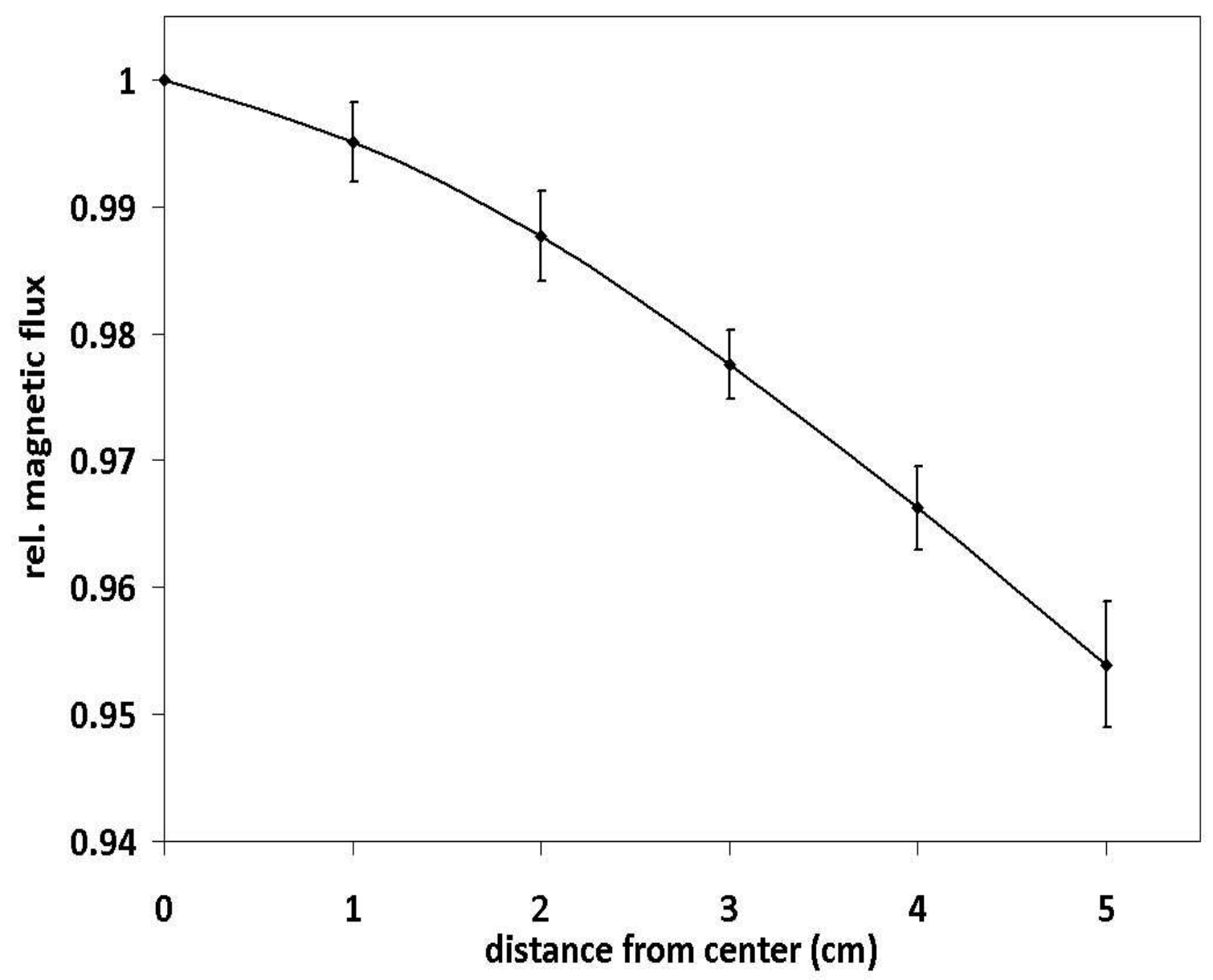

Figure 2. Homogeneity of the magnetic field around the centre of the solenoid used for the experiments, shown as ratio to the maximum in the centre. The magnetic flux radially decays from the centre to the rim of the flow cell $(r=4.5 \mathrm{~cm})$ by $\sim 4 \%$. The error bars show the aberration on a certain distance for 4 directions shifted rectangular against each other.

to $13 \mu \mathrm{m}$ (Stas'kov and Ivashkevich 2008). The referencing air temperature was monitored by a plastic coated copper probe directly above the water which was visible at one edge of the thermogram (figure 1). The emission grade was $\geq 0.95$ in any case by a nominal sensitivity of $0.1^{\circ} \mathrm{C}$. By averaging over 16 subsequently recorded thermograms and bunching of 88 pixels, the actual thermal resolution of the image after processing was enhanced to $0.012^{\circ} \mathrm{C}$. The thermocouples as well the IR-camera were calibrated in the range of -2 to $+35^{\circ} \mathrm{C}$ against a digital thermometer for laboratory use with high accuracy.

Initially, the air temperature was $1.0 \pm 0.1^{\circ} \mathrm{C}$ above that of the bath. In the centre of the flow cell, a Peltier element (Kryotherm $\AA$ TB-127) was mounted. Its top side was thermally connected to a copper finger, which could generate radial temperature profiles in the bath from the centre to the rim. The bottom side of the Peltier element was maintained at the reference temperature $T_{0}=8^{\circ} \mathrm{C}$. The electric power of $3.5 \pm 0.01 \mathrm{~W}$ of the Peltier element was provided by an adjustable, high stable power supply, which also was connected to the control computer. A cylindrical solenoid, generating the vertical MF, was concentrically mounted below the cuvette in a separate water thermostated copper housing, in order to ensure optimal temperature decoupling from the flow cell (figure 1). The MF could be set to $B_{z}=0,30,42.5$ and $60 \mathrm{mT}$, according to the quadratic dependence of the magnetic interaction parameter $N$ from $B_{z}$ (meaning ratios of $N$ 0:0.25:0.5:1). The magnetic flux and homogeneity of the MF was determined by a Hall magnetometer (type: Fieldmeter H1-4, Magnet-Messtechnik Jrgen 
Ballanyi e.K.).

Each convection experiment started with generating a radial temperature gradient in the bath by heating with the Peltier element over $100 \mathrm{~s}$. During a subsequent equilibration phase, the change of the resulting temperature profile was monitored in the water layer and recorded up to $800 \mathrm{~s}$ for the bath, the water-air surface, and the airspace directly above. Published seawater standard data were used for calibration and calculations (Sharqawy et al. 2010, Vialard and Delecluse 1998, Fofonoff 1985).

\section{Experimental results and discussion}

Prior to the measuring the influence of a MF on the heat transport in the seawater bath some calibrations and error estimations were performed. The radial homogeneity of the MF inside the flow cell was tested by the magnetometer. It decreased from the centre to the rim by only $4.6 \%$. This should be sufficient for purpose, the direction dependent aberration for certain distances averaged to $0.35 \%$ (for radial resolved data see supplemental figure 2. Also the long term drift of output was $<0.5 \%$ per hour at $60 \mathrm{mT}$. No transmission of waste heat from the solenoid to the bath was detectable by the available sensitivity, by either the thermocouples or the IR-camera.

\begin{tabular}{|c|c|c|c|c|c|c|}
\hline & & Dist. water & $\begin{array}{l}\text { Seawater } \\
35 \mathrm{PSU}\end{array}$ & $\mathrm{NaCl}$ & $5 \%$ & $\mathrm{NaCl} 10 \%$ \\
\hline Density & $\rho \mathrm{Kg} \mathrm{m}^{-3}$ & 998.0 & 1024.9 & & 1034 & 1070.7 \\
\hline Dynamic viscosity & $\begin{array}{l}\mu 10^{-3} \mathrm{~s} \\
\mathrm{~m}^{-2} \mathrm{~N}^{-1}\end{array}$ & 1.002 & 1.077 & & 1.049 & 1.115 \\
\hline Kinematic viscosity & $\nu 10^{-6} \mathrm{~m}^{2} \mathrm{~s}^{-1}$ & 1.004 & 1.050 & & 1.015 & 1.041 \\
\hline Thermal diffusivity & a $10^{-7} \mathrm{~m}^{2} \mathrm{~s}^{-1}$ & 1.446 & 1.470 & & 1.427 & 1.416 \\
\hline Heat conductivity & $\lambda \mathrm{W} \mathrm{K}^{-1} \mathrm{~m}^{-1}$ & 0.6035 & 0.6016 & & 0.5988 & 0.5941 \\
\hline Specific heat capacity & $\mathrm{C}_{p} \mathrm{~J} \mathrm{Kg}^{-1} \mathrm{~K}^{-1}$ & 4182 & 3994 & & 4057 & 3919 \\
\hline Electric conductivity & $\sigma \Omega^{-1} \mathrm{~m}^{-1}$ & $\leq 10^{-6}$ & 4.79 & & 7.01 & 12.60 \\
\hline Prandtl number & $\operatorname{Pr}$ & 6.94 & 7.15 & & 7.11 & 7.36 \\
\hline
\end{tabular}

Table 2. Thermodynamic properties of aqueous solutions used as fluids for the experiments. All data relate to $T=20^{\circ} \mathrm{C}$. Data for seawater were calculated by the algorithms of (Sharqawy et al. 2010), the other were determined by (Riedel 1951, Weast 1986)

As expected, a bath of distilled water showed no measurable change of heat flow, when an MF was applied in the feasible range up to $60 \mathrm{mT}$. The basic thermodynamic properties of the aqueous solutions used as fluids are composed in table 2. The main experiments were performed with artificial seawater at a salinity of 35 PSU according to the issue of this work. But accompanying results obtained by $\mathrm{NaCl}$ solutions confirmed that the electric conductivity $\sigma$ was the governing fluid property for the magnetic effect. As mentioned above, the two dimensional temperature distribution on the surface of the seawater bath was investigated by thermal imaging. Figure 3 shows the surface temperature distribution $72 \mathrm{~s}$ after initial heating in the centre $(3.5 \mathrm{~W}, 100 \mathrm{~s})$ stopped, in the absence (figure $3(\mathrm{a})$ ) and the presence (figure 3(b)) of a vertical MF of $B=60 \mathrm{mT}$. In the latter case the temperature of the inner region of the bath is distinctly warmer, suggesting that the horizontal heat flow is slowed down by the MF. The two diagrams (figure $3(\mathrm{c}, \mathrm{d})$ ) show the surface temperature profiles along the cross-sections L01 and L02 each marked in the thermal images above. L02 additionally includes a small sheet of coated copper in the air space above the bath, in order to indicate the air temperature $T_{\text {air }}$, It is slightly increased by the MF effect due to the enhanced heat accumulation in the bath below, yet it leads to a loss of surface heat flux of $27.1 \mathrm{~W} \mathrm{~m}^{-2}$ in the horizontal direction and $15.9 \mathrm{~W} \mathrm{~m}^{-2}$ through the surface. Extrapolating these effects, convection should be completely 
a
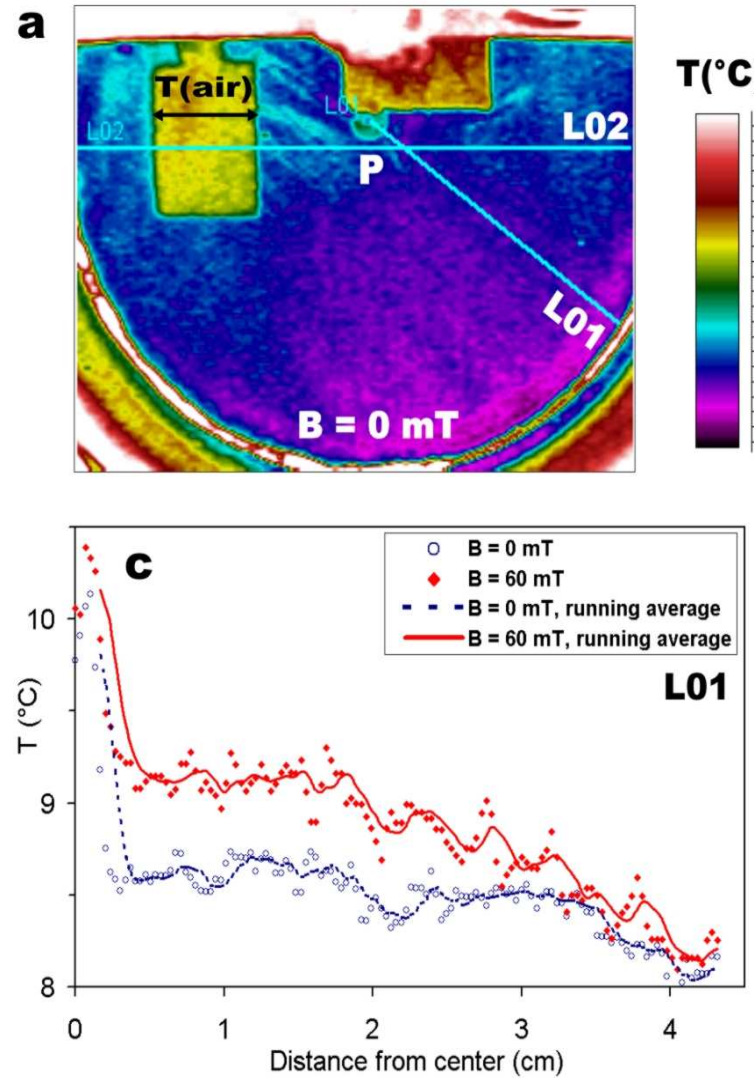

b
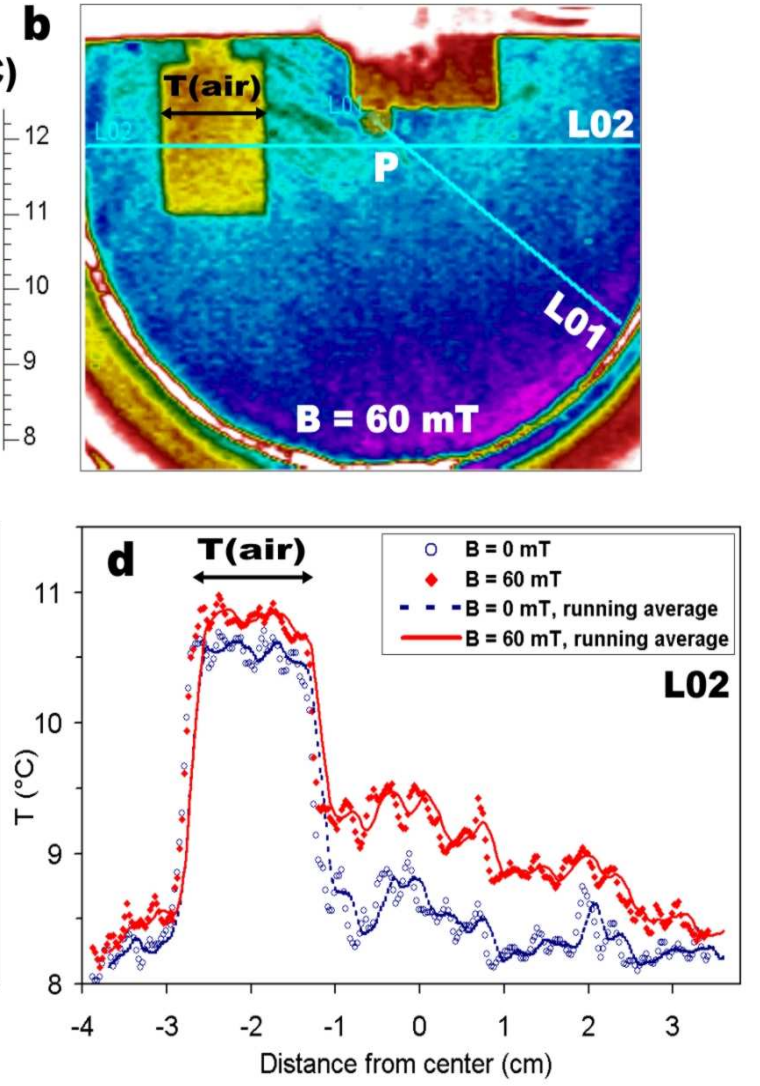

Figure 3. Thermal images (a, b) of the surface of the seawater bath (salinity 35 PSU) and temperature profiles along lines L01 (c) and L02 (d). T(air)三 $T_{\text {air }}$ : A small copper plate horizontally mounted $5 \mathrm{~mm}$ above the water surface and trimmed to the emission factor of water $(\sim 0.95)$ by suitable coating assumed the air temperature directly above the bath. Images were recorded after initial heating $(3.5 \mathrm{~W}, 100 \mathrm{~s})$ by the centrally mounted Peltier finger $(\mathrm{P})$ and a subsequent equilibration phase of $200 \mathrm{~s}$ with no additional heat supply. In (b) a vertical MF of $B=60 \mathrm{mT}$ was applied with (a) $(B \leq 0.05 \mathrm{mT})$ serving as control. Temperatures are colour coded according to the scale between the images. The spreading and drain of the accumulated heat proceeded slower in the MF (rhomb symbols and solid lines for averages averages running about 8 successive values each in $(\mathrm{c}, \mathrm{d})$ compared to the experiment with no MF (circle symbols and dotted lines for running averages). The heat dissipation to the air is conversely increased as a whole in the MF experiment (b), but the lower ratio to the surface temperature possibly indicates also a decreased heat flux parallel to the MF, as suggested before (Genin et al. 1970, Kenjeres and Hanjalic 2004).

inhibited in the existing set-up by a MF of about $0.7 \mathrm{~T}(\mathrm{Ha}=2.0)$. At a MF of $60 \mathrm{mT}$, the lateral heat flux $q_{\text {Lat }}$ (perpendicular to the MF) was $293.5 \pm 2.5 \mathrm{~W} \mathrm{~m}^{-2}$. Compared to the reference value of $320.6 \pm 1.4 \mathrm{~W} \mathrm{~m}^{-2}$ at the environmental magnetic field $\left(B_{z}<0.05 \mathrm{mT}\right)$, this corresponds to a decrease $8.47 \pm 1.17 \%$. The surface heat flux $q_{S}$ (parallel to the MF) was even reduced by $13.8 \pm 1.45 \%$, resulting in a ratio $q_{S} / q_{\text {Lat }}$ of 0.34 . The data from experiments at this and two lower MF fluxes (30 and $42.5 \mathrm{mT}$ corresponding to an average magnetic interaction parameter $N$ of $0.29 \cdot 10^{-3}$ and $0.58 \cdot 10^{-3}$, respectively) are given in table 3 . Relative to $\Delta N=10^{-3}$, the average reduction of lateral heat flux was $7.79 \pm 0.3 \%$, for the water-air surface it was still larger, namely $12.4 \pm 0.9 \%$. The ratios of surface to lateral heat flux would slightly reduce for rising $B_{z}$, but on the whole, the decrease of both, surface and lateral heat flux related to the magnetic flux is linear in good approximation. This linearity should be limited to small $N<0.005$ : due to the nonlinear relation of Rayleigh and Nusselt numbers, $R a$ will be progressively reduced by an increasing Stuart number $N$.

The temperature profiles shown on logarithmic timescale (figure 4(a)) illustrate the time dependence of heat flux damping in the presence of a MF of $60 \mathrm{mT}$. Because of the geometry of the assembly a horizontal circulation in the bath ensued between the centre and the outside 


\begin{tabular}{|c|c|c|c|c|}
\hline Magnetic flux density $B[\mathrm{mT}]$ & $<0.05$ & 30 & 42.5 & 60 \\
\hline Average $N\left(\cdot 10^{-3}\right)$ & $\sim 0$ & 0.290 & 0.582 & 1.16 \\
\hline Number of experiments & 21 & 22 & 35 & 37 \\
\hline Transported lateral heat $Q_{\text {Lat }}[\mathrm{J}]$ after $300 \mathrm{~s}$ & $131.2 \pm 0.57$ & $128.1 \pm 0.65$ & $124.9 \pm 1.06$ & $120.1 \pm 1.01$ \\
\hline Change of $Q_{\text {Lat }}[\mathrm{n}]$ & - & -3.06 & -6.24 & -11.11 \\
\hline Averaged lateral heat flux $q_{\text {Lat }}\left[\mathrm{W} \mathrm{m}{ }^{-2}\right]$ & 320.6 & 313.2 & 305.4 & 293.5 \\
\hline Decrease of $q_{\text {Lat }}$ in $\%$ & - & $2.33 \pm 0.95$ & $4.75 \pm 0.84$ & $8.47 \pm 1.17$ \\
\hline Transported surface heat $Q_{S}[\mathrm{~J}]$ after $300 \mathrm{~s}$ & $211 \pm 1.86$ & $202.7 \pm 2.27$ & $196.3 \pm 2.43$ & $181.9 \pm 4.02$ \\
\hline Change of $Q_{a}[\mathrm{~J}]$ & - & 8.27 & 14.70 & 29.11 \\
\hline Averaged surface heat flux $q_{S}\left[\mathrm{~W} \mathrm{~m}^{-2}\right]$ & 115.6 & 111.1 & 107.6 & 99.7 \\
\hline Decrease of $q_{S}$ in $\%$ & - & $3.92 \pm 1.12$ & $6.97 \pm 1.06$ & $13.80 \pm 1.45$ \\
\hline Ratio of $q_{a} / q_{\text {Lat }}$ & 0.361 & 0.355 & 0.352 & 0.340 \\
\hline Ratio of decrease of $q_{S} / q_{\text {Lat }}$ & 1.00 & 0.984 & 0.977 & 0.942 \\
\hline
\end{tabular}

Table 3. Magnetic field (MF) effect on the lateral (perpendicular) $\left(q_{\text {Lat }}\right)$ and surface (horizontal) heat flux $\left(q_{S}\right)$ in seawater (salinity 35 PSU). A static magnetic field, $B$, of 30, 42.5 and $60 \mathrm{mT}$ was applied, corresponding to the ratio of $1: 2: 4$ of the magnetic interaction parameter $N$ (Stuart number). In the control, with the electromagnet switched off, the background field, $\mathrm{B}$, was found to be $<0.05 \mathrm{mT}$. In both experimental situations the seawater was initially heated for $100 \mathrm{~s}$ in the centre of the circular cell with $3.5 \mathrm{~W}$ for $100 \mathrm{~s}$. The copper enclosure of the cell was maintained at constant temperature and served as a lateral heat drain. In the subsequent measuring phase, the heat transfer is reduced by the applied MF. The effect is correlated to the magnetic interaction parameter $N$ and increases also with the temperature, as is predicted for MF interactions with negligible magnetic induction (Hanjalic and Kenjeres 2002). Heat transport data are calculated from the temperature data, which were obtained with high precision by thermocouples (lateral) and an IR-camera (surface).

border, which could be deduced by the thermal images yielded from the surface. Additionally, the radial temperature distributions in the flow cell for some different times without a MF are shown for seawater (35 PSU) in the supplemental file (figure 5). After initial heating the exponential decay of temperature equilibration begins at $t=0 \mathrm{~s}$ and is nearly complete after about $300 \mathrm{~s}$ (figure 5 and figure $4(\mathrm{a})$ ).

A more accurate analysis was tried using the differences of the temperature profiles with and without a magnetic field. The difference reaches a maximum $\Delta T=0.85 \pm 0.06 \mathrm{~K}$ at a radial distance $r(1)=7 \mathrm{~mm}$ and $\Delta T=0.36 \pm 0.04 \mathrm{~K}$ at $r(2)=22 \mathrm{~mm}$ after $\tau_{1} \sim 72 \pm 2 \mathrm{~s}$ (figure 4(a)). The most significant effect is an over-compensation until $\tau_{1}$ of the cool down given by the surface- and lateral heat flux (figure 4(b)). At the beginning the major part of the heat flux is limited to the inner regions around the centre with strong convection. Then the heat will increasingly distribute over the entire cell volume, and the accelerating heat drain continuously overcomes the retention of heat by the magnetic interaction. Considering this fact, a modeling of heat retention by magnetic interaction and the resulting temperature profile sufficiently match the experimental data (solid line in figure 4(b)).

The average Rayleigh numbers $R a$ of the bath were 13400 (at $0 \mathrm{mT}$ ) and 12200 (at $60 \mathrm{mT}$ ), whereby the critical Rayleigh number $R a_{c}$ for onset of convection were 1280 and 1096 in good accordance with the criteria in Baranowski et al. (1972).

Their time courses also show the expansion to the largest difference caused by magnetic interaction during the first $100 \mathrm{~s}$; figure 4 (c) shows $R a-R a_{c}$. Afterwards the difference slowly levels off, but remains clearly lower for the experiments with $B=60 \mathrm{mT}$, reaching $R a \sim R a_{c}$ here after $300 \mathrm{~s}$. The decrease of $R a \rightarrow R a_{c}$ for both cases is demonstrated in figure 4(d), where $R a /\left(R a-R a_{c}\right)$ reaches values $<0.5$. For the experiments with $B=60 \mathrm{mT}$ this condition is just not reached after $300 \mathrm{~s}$, considering the slope of $R a_{c}$ with rising $H a$ (as treated in Cioni et al. 2000, Kenjeres and Hanjalic 2004).

Effects of the convective flow on the local temperature distribution by changes are often visualised by shadow graph images (Andreev et al. 2003). In the present work, the convection process has been visualised by thermograms of the bath surface (figure $6(\mathrm{a}-\mathrm{c})$ ). Due to the strong absorption of infrared light (IR) by water, only the top layer of contributes to the 

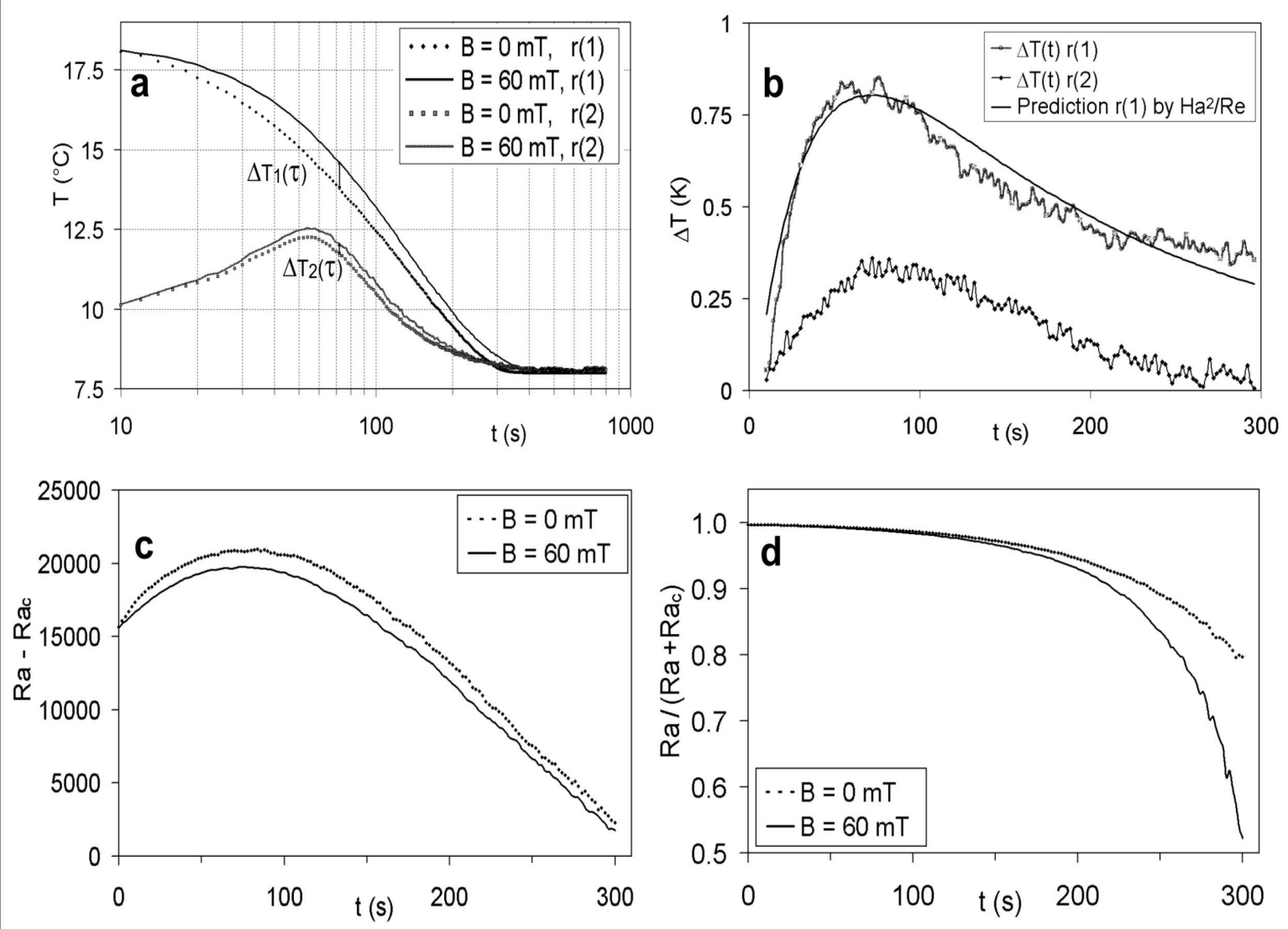

Figure 4. (a) Effect of a vertical magnetic field $B=60 \mathrm{mT}$ on the thermal equilibration of seawater (35 PSU) in the circular flow cell (see figure1). The bath was initially equilibrated to $T_{0}=8^{\circ} \mathrm{C}$ and then heated for $100 \mathrm{~s}$ by a Peltier finger in the centre, reaching $T_{\max }=18^{\circ} \mathrm{C}$ at $r(1)=7 \mathrm{~mm}$ (upper curves) and $12.5^{\circ} \mathrm{C}$ delayed after another $55 \mathrm{~s}$, at $r(2)=22 \mathrm{~mm}$ distance from the centre (lower curves). The subsequent temperature equalisation shown here by the lateral and surface heat drain was reduced by the MF (solid lines) compared to the reference profiles without MF (doted lines).

(b) Differences of the temperature profiles given in (a) After $\tau \sim 72 \pm 2 \mathrm{~s}$, the maximum difference of $\Delta T_{1}=0.85 \pm 0.06 \mathrm{~K}$ is seen at $r(1)$ and of $\Delta T_{2}=0.36 \pm 0.04 \mathrm{~K}$ at $r(2)$. At longer times the temperature difference decreases approximately exponential, as expected, because the heat continues spreading and drains away over a steadily increasing area. The curve fit (black solid line) models the differential temperature profile at $r(1)$, assuming that the braking of convection would be exclusively governed by the Stuart number $N$.

(c) Time curves of $R a-R a_{c}$, namely the Rayleigh number $R a$ less the critical Rayleigh number $R a_{c}$ at $r(1)$, with (solid line) and without (dotted line) an applied vertical MF of $60 \mathrm{mT}$. The maximum reduction of $R a$ by will be reached in the first $100 \mathrm{~s} ; R a>R a_{c}$ remains valid for the first $300 \mathrm{~s}$.

(d) The estimation of onset and stability of convection by $R a /\left(R a+R a_{c}\right)$ with (solid line) and without (dotted line) a vertical $\mathrm{MF}$ of $B=60 \mathrm{mT}$ : At the low values of $R a$ occurring in the experiments the damping of convective flow by the MF nearly reaches $R a_{c}$ after $300 \mathrm{~s}$, which means, that further thermal equilibration should solely proceed by heat conduction.

signal, and only the top 5-10 $\mu \mathrm{m}$ of the convection cells will be visualised. The thermogram in figure 6(a) shows the difference of surface temperatures of experiments at $B=60 \mathrm{mT}$ and $B<0.05 \mathrm{mT}$. Because the heat flux in the MF is delayed, a concentric belt of maximum temperature difference exists. This effect is notably developed around $\sim 72 \mathrm{~s}$ after beginning of the temperature equilibration. After filtering the thermal images in a wave number range of $2-10 \mathrm{~cm}^{-1}$ by $2 \mathrm{D}$-fast Fourier transformation (FFT), local temperature inhomogeneities can be seen on a scale $<0.5 \mathrm{~cm}$. Without a MF small warmer and colder regions alternate more or less by equal parts (figure 6(b)), but a MF of $60 \mathrm{mT}$ causes steeper and more constricted walls between the convection cells (figure 6(c)). The basic mechanism of damping convective flows in a MF by Lorentz force interaction predicted by De Luca (2009) and Kazaryan et al. (2010) is confirmed by these experiments. 


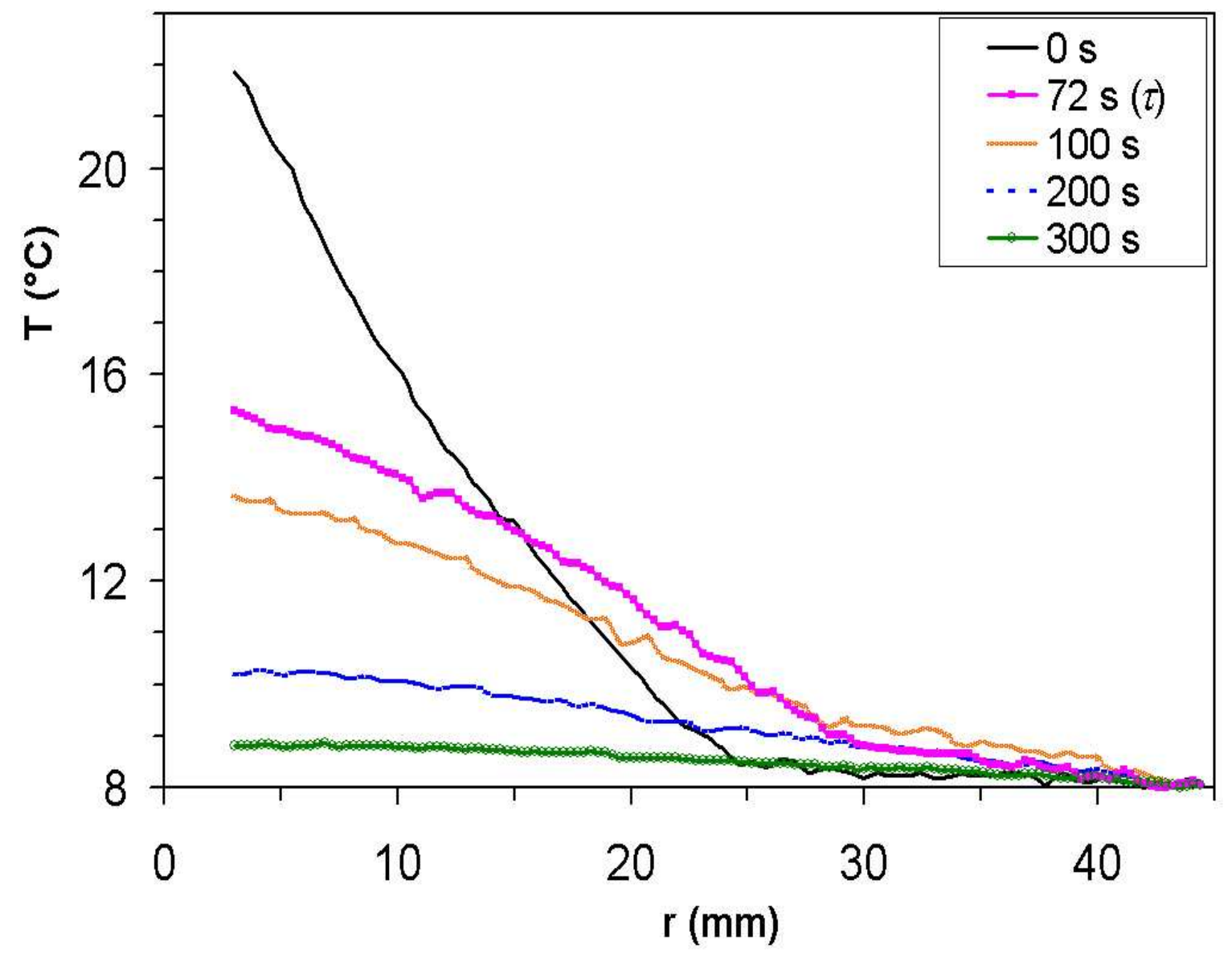

Figure 5. Temperature distribution in the radial flow cell during equilibration at $t=0,72(=\tau), 100,200$ and $300 \mathrm{~s}$. Shown are averages of 5 experiments with seawater (salinity 35 PSU) in the absence of a MF each. The centre up to $r=3 \mathrm{~mm}$ is filled by the vertical copper finger of the heater (see also figure 1 for experimental setup).

The dimensionless ratio of convective to conductive heat transfer across a geometrydependent boundary can be expressed by the Nusselt number $N u$, which allows comparing fluid-mechanical similarities with other systems. The relation of $R a$ and $N u$ for the experimental data are depicted in (figure $7(\mathrm{a})$ ), which give averaged $N u$ of 15.4 and 12.2 for $B=0$ and $60 \mathrm{mT}$, respectively, the overlayed curves (solid lines) show the best fits. The "classical" estimation $N u=0.15 R a^{0.43}$ matches well for the experiments without a MF $(H a=0)$, for these with a MF a best fit was found by $N u=3.35710^{-3} \mathrm{Ra}^{0.46} \mathrm{Ha}^{-2}$ with an reasonable small error of $\Delta N u=0.55$. For comparison, the function $N u=0.1 R a^{0.43} \mathrm{Ha}^{-0.5}$ (dashed line in figure $7(\mathrm{a})$ ) suggested by Cioni et al. (2000) results in an error of $\Delta N u=1.17$ for the given data.

Sea salt cannot be completely dissolved at concentrations of $>5 \%$. For extending the experiments to higher conductivities, solutions of $5 \%$ and $10 \% \mathrm{NaCl}(\mathrm{w} / \mathrm{w})$ were used instead of sea salt, which resulted in a reliable significance also for the experiments at lower magnetic fluxes of 30 and $42.5 \mathrm{mT}$. Additional data were obtained for $B=20 \mathrm{mT}$ and $50 \mathrm{mT}$ for $10 \% \mathrm{NaCl}$. These data were included in order to relate the decrease of $N u$ for rising magnetic interaction $N$ (figure $7(\mathrm{~b})$ ). Since the absolute values of $N u$ strongly depend on the experimental geometry, the relative change $N u=\left(N u_{B}-1\right) /\left(N u_{0}-1\right)$ with $N u_{B}$ for the relevant experiments using $N>0$ was selected here for presentation. The dotted straight line marks the average observed gradient of about $N u^{*}=1-\ln (1-76.3 N)$, the minimal mean error is $4.17 \cdot 10^{-3}$.

These results show that heat transfer in seawater is significantly affected by an external static 

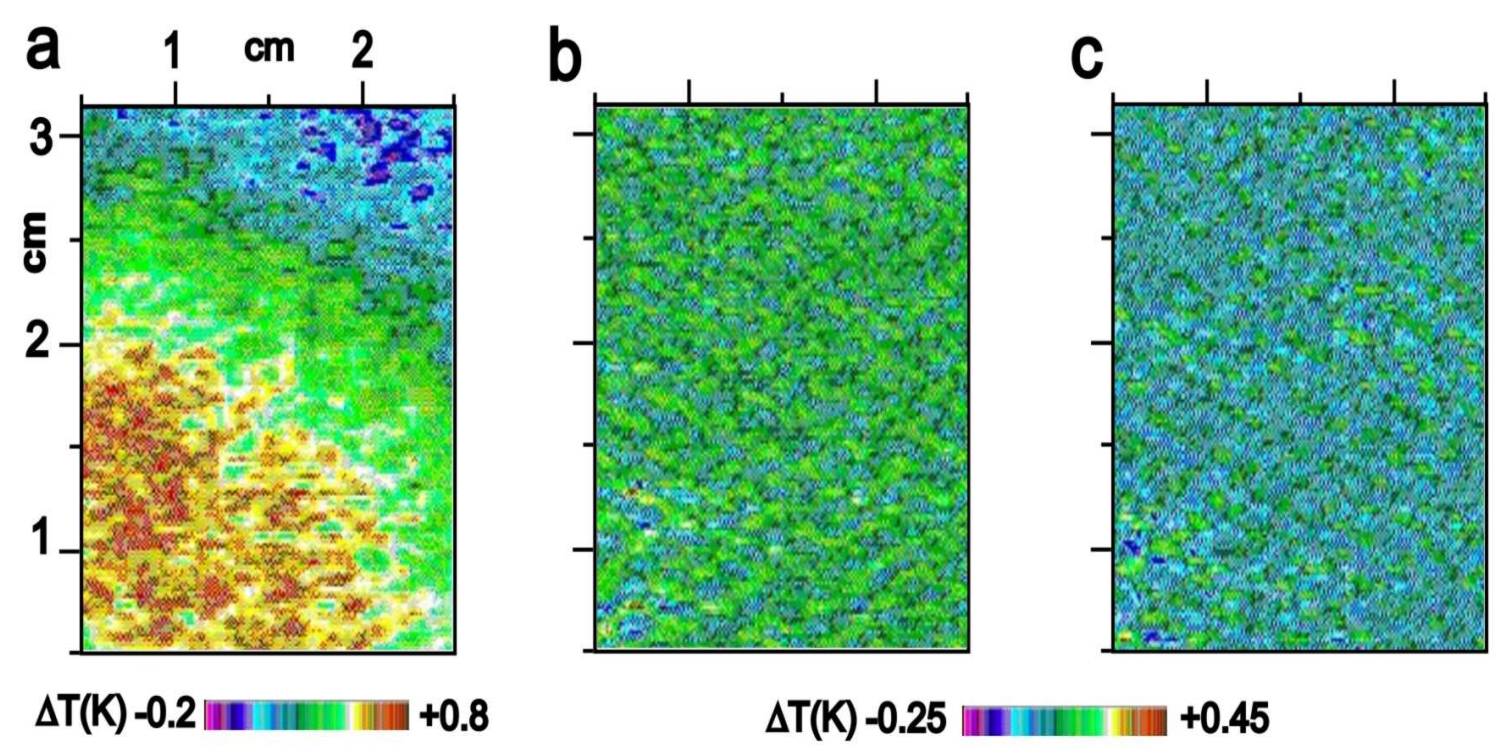

$\Delta \mathrm{T}(\mathrm{K})-\mathbf{0 . 2 5}$

Figure 6. Visualisation of the local temperatures on the surface by thermal surface images $72 \mathrm{~s}$ after the beginning of the thermal equilibration phase. An image section of about $20 \times 28 \mathrm{~mm}$ inside the measuring cell is selected, the centre is located at the lower left corner, the heat flow is consequently directed to the upper right corner of the images. Temperatures are colour coded by the scales.

(a) Temperature differences between experiments at $B=60 \mathrm{mT}$ and $B=0 \mathrm{mT}$ (no MF). Due to the magnetic braking of convection, the horizontal heat propagation is delayed, resulting in a zone of maximum temperature difference $\Delta T_{\max }$ is mainly governed by the magnetic interaction parameter $N$ (see figure 4(b)).

(b) and (c) Two dimensional Fourier filterings of the temperature profiles obtained at the wave number range (spatial frequency) of 2-10 $\mathrm{cm}^{-1}$. (b) Without an $\mathrm{MF}(B=0 \mathrm{mT})$ temperature inhomogeneities tightly cover large regions and indicate convection cells. (c) In a MF $(B=60 \mathrm{mT})$, regions of local convection are less tight and distributed more irregularly.

MF. The reduction of heat flux is monotonously correlated with the magnetic parameter $N$, (5b), while the amount of spatially redistributed heat $\Delta Q$ leads to a turnover time $\tau$ given by the defined system, here $\tau \sim 72 \mathrm{~s}$ for seawater (35 PSU), which does not significantly depend on the selected magnetic fluxes $(30,42.5$ or $60 \mathrm{mT})$. Surprisingly, the experiments indicated that the relationship of $\Delta Q \equiv B \tau$ matches well for a wide range of $N$ for a given conductivity $\sigma$ and viscosity $\nu$ for a fluid species, e.g. seawater or $\mathrm{NaCl}$-solutions with different salt concentrations. Probably, $\tau$ was increased for solutions of $5 \% \mathrm{NaCl}(77 \pm 2 \mathrm{~s})$ and $10 \%$ $\mathrm{NaCl}(84 \pm 2 \mathrm{~s})$, having different $\sigma$ and $\nu$. This confirms earlier models of free, magneticallyinfluenced convection (Nadoor and Bhattacharyya 1981, Kenjeres 2008, Hanjalic and Kenjeres 2001).

The occurrence of a maximum of heat accumulation in the bath after a discrete time interval $\tau$ can be explained by two competing processes, the heat distribution in the flow cell on the one hand, and the formation of the Hartmann layer on the other hand. The latter then rises with higher local gradients of temperature, heat and mass flux that exist at the beginning of the experiment. After time $\tau$ the mean bath temperature $T_{m}$ in an applied MF of $B=60 \mathrm{mT}$ amounts to $\Delta T_{m}=+0.28 \pm 0.02 \mathrm{~K}$ above the values obtained by the reference experiments without an MF: this would be in accordance with magnetic damping in the standard turbulence model for $\tau \sim k / \varepsilon$. For the experimental setup we get a total magnetic braking time $t_{m}=7.7 \cdot 10^{4} \mathrm{~s}$ according to equation (9), which is the about thousand times $\tau$. The heat accumulation $\Delta Q$, causing the average temperature increase $\Delta T_{m}$ in the bath volume, can be expressed by using the absolute (Kelvin-) temperature for $T_{m}$ as

$$
\Delta T_{m}=\frac{\tau}{t_{m}} T_{m(B=0)} .
$$



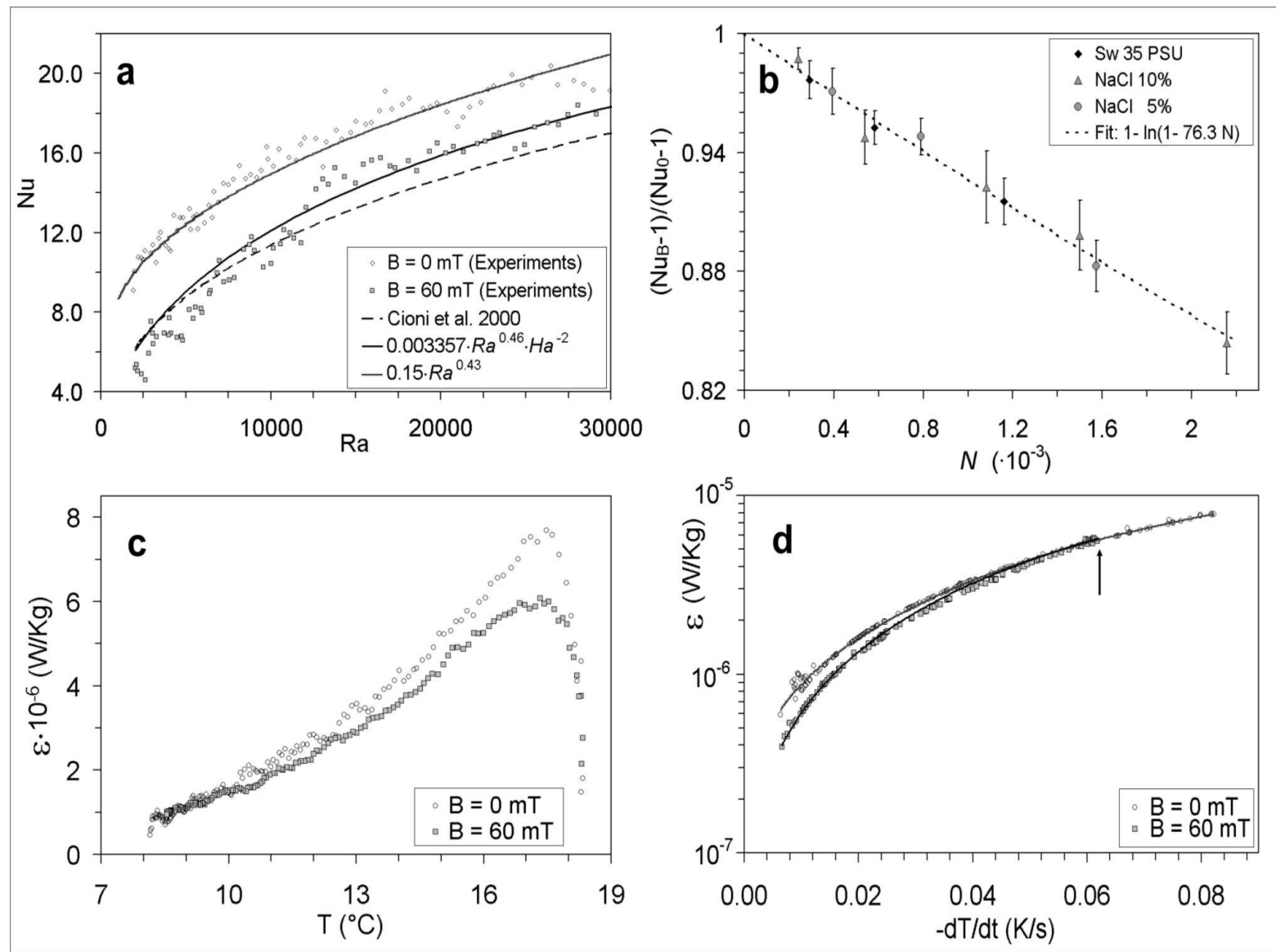

Figure 7. (a) The relation of the Rayleigh- and Nusselt-numbers for experimental surface heat transfer data for a vertical $\mathrm{MF}$ of $B=60 \mathrm{mT}$ (shaded square symbols) and $B=0 \mathrm{mT}$ (circles): Without a MF the common estimation of $N u=0.15 R a^{0.43}$ is sufficiently reached (Fit $B=0 \mathrm{mT}$ ). By applying a vertical MF of $B=60 \mathrm{mT}, N u$ decreases according to breaked heat flux $q$. Fitting the data by the hypothesised $H a^{2}$ dependency for the heat flux reduction leads with $\mathrm{Nu}=3.35710^{-3} \mathrm{Ra}^{0.46} \mathrm{Ha}^{-2}$ to a more accurate approximation of the data at these low Ha numbers like $N u=0.1 R a^{0.43} Q^{-0.25}$ (with $Q=H a^{2}$ ) suggested by Cioni et al. (2000).

(b) Dependence of the heat flux decrease, expressed by the relative Nusselt number $N u^{*}=\left(N u_{B}-1\right) /\left(N u_{0}-1\right)$, by the magnetic interaction parameter $N$ (Stuart number), for experiments with fluids having different electrical conductivities $\sigma$ and different vertical magnetic fluxes $B(60,42.5$ and $30 \mathrm{mT}) . N$ relates the electromagnetic and viscous forces according to $N=\mathrm{Ha}^{2} \mathrm{Pr} / \mathrm{Pe}$, where $\mathrm{Pr}$ is the Prandtl number and $\mathrm{Pe}$ is the Peclet number. The best fit results in $N u^{*}=1-\ln (1-76.3 N)$. NaCl solutions behave very similar to seawater, mainly effecting to $B^{2} \sigma$.

(c) Dissipation rates of turbulence $(\varepsilon)$ for seawater (salinity 35 PSU) at time $\tau$ as a function of temperature. Beyond the average bath temperature $T_{a} \sim 1.3^{\circ} \mathrm{C}$ the dissipation rate is clearly damped in a MF with $B=60 \mathrm{mT}$ (filled squares) compared to experiments without a MF (circles).

(d) Dissipation rates of turbulence $(\varepsilon)$ for seawater (salinity 35 PSU) as a function of the temporal temperature gradient. $\varepsilon$ is consistently lower for experiments in a MF with $B=60 \mathrm{mT}$ (filled squares). In this case temporal temperature gradients were always lower than $-0.06 \mathrm{~K} / \mathrm{s}$ (arrow).

This agrees well with the experimentally-determined value for $\Delta T_{m}$. Because of the smallsystem size and accordingly a rapid turbulence dissipation process, we expect only negligible effects by differential diffusion of heat and salt, which is obviously larger for heat (bulk flow length $L_{0}$, mass- diffusivity $D$, elapsed time $t$ ):

$$
\frac{\alpha_{T} L_{0}}{C \rho} q_{\text {net }}=\alpha_{T}(-a \Delta T) \gg \beta_{S}(-D S) \quad \text { and } \quad t \rightarrow \tau .
$$

Thus $\varepsilon$ and $k$ in the temperature equilibrium phase $T_{m}(t) \rightarrow T_{m}\left(t_{\infty}\right)$ will be expressed for the sample volume $V$ and total area of heat transfer $A$ by

$$
k(t)=g L_{0} \alpha_{T}\left|T_{m}(t)-T_{m}\left(t_{\infty}\right)\right|, \quad \varepsilon(t)=\frac{\mathrm{d} k}{\mathrm{~d} t}=\frac{k\left(t_{2}\right)-k\left(t_{1}\right)}{t_{2}-t_{1}} .
$$


$Q_{T}$ is the residual thermal energy above the reference temperature $T_{m}\left(t_{\infty}\right)$ of the bath (in Joules) respectively. The dependence of the dissipation rate $\varepsilon$ on the local temperature was modeled using the $T$-distributions obtained by the IR-camera and are shown in (figure $7(\mathrm{c})$ ). Changes of $\varepsilon$ in time are plotted against the time gradient of $T$ (figure $7(\mathrm{~d})$ ). A definite change of $T$ generates a smaller change of $\varepsilon$ in experiments with a MF, additionally the temperature gradient $\mathrm{d} T / \mathrm{d} t$ roughly did not exceed $0.06 \mathrm{~K} / \mathrm{s}$ in this case for $B=60 \mathrm{mT}$.

The local maximum temperature increase $\Delta T(r, \tau)$ for a given Stuart number $N$ at radius $r$ after the assumed turn over time $\tau$ and the heat already drained horizontally and by the surface can be estimated by $T_{m}(\tau)$ to be

$$
\Delta T(r, \tau)=T_{m}(\tau) N\left(1-\frac{1}{Q_{T}} \int_{0}^{\tau}\left(q_{1} A_{1}+q_{2} A_{2}\right) \mathrm{d} \tau\right) .
$$

The integral term normalises the heat already transferred by the surface, $A_{1}=\left(r^{2}-r_{m}^{2}\right) \pi-A$, and the area of horizontal flux $A_{2}=2\left(r-r_{m}\right) \pi h$ of the measuring cell, where $h$ is the layer thickness, $r_{m}$ the distance, $T_{m}$ matches the local temperature, and $A$ the central surface area covered by the heater. The error of this estimate against the experimental values for $\Delta T(r, \tau)$ will give $<7 \%$.

Finally the turnover time in the flow cell was determined from the convective flow. By considering a more or less uniform vorticity, we can estimate an average size $L_{c}$ of the convection rolls by using a non-dimensional time $N_{b} \tau$ with the buoyancy (Brunt-Väisälä) frequency $N_{b}$ :

$$
L_{c}=\frac{L_{0} 2 \pi}{N_{b} \tau} \quad \text { with } \quad N_{b}=\sqrt{-\frac{g}{\rho} \frac{\mathrm{d} \rho}{\mathrm{d} z}} .
$$

It amounts to $\sim 3.29$ rolls $/ \mathrm{cm}$ for $\tau=72 \mathrm{~s}$, which fits very well with the small-scale surface temperature patterns seen in (figure 6(b,c)). Accordingly, the size of the convective structures lies not too far above the average Kolmogorov length $\eta=\left(\nu^{3} / \varepsilon\right)^{0.25} \sim 1.5 \mathrm{~mm}$ in the system, fully covering the dissipation scale end of the turbulent energy spectrum with low Reynolds numbers. This situation is primarily also applicable to the deep layers in large natural waters, where the vertical mixing is low, prevalently transitioning into stratified turbulence. Then the turn over time $\tau$ for a distinct layer of thickness $d_{z}$ in the vertical direction will be governed by the buoyancy flux $b_{f}$ (see (1)) and the buoyancy anomaly

$$
g^{\prime}=g \frac{\rho\left(d_{z}\right)-\rho_{0}}{\rho_{0}}
$$

(see also (2)). A Peclet number $P e_{z}$ can be defined as

$$
P e_{z}=\frac{b_{f} d_{z} \rho C}{g^{\prime} \lambda}=\frac{d_{z}^{2} \rho C}{\tau \lambda} \quad \text { with } \quad \lim _{\dot{Q}, \dot{C}} \frac{d_{z}}{N_{b} \tau}=\left(\frac{\nu^{3}}{b_{f}}\right)^{1 / 4}
$$

where $\dot{Q}=\mathrm{d} Q / \mathrm{d} t, \dot{C}=\mathrm{d} C / \mathrm{d} t$. This agrees well with the fact that the continuously new production of turbulence in a certain water volume results from the bulk in- or out-flux of heat $|\dot{Q} / Q|$, and salt concentration $|\dot{C} / C|$. In the deep sea, the dissipation rate is still 2-3 orders closer to the end of the Kolmogorov scale than in the experiments described here, because of the large gravitational work required for vertical movement. Consequently, the turn over time is usually very large, up to several decades per $100 \mathrm{~m}$ depth in the open sea far away from any boundaries. The $H a$ number in the sea caused by the vertical geomagnetic component $B_{z}$ reaches approximately 1 for the upper $500 \mathrm{~m}$ of the ocean, if calculated using suitable data provided by public sources (Finlay et al. 2010, Antonov et al. 2006, Locarnini et al. 2006). During the last 150 years the variation of the geomagnetic field is large compared to the centuries before (Jackson et al. 2000). We tried to visualise this fact using gridded maps for the time span of 1960-2000. Map (a) of the supplemental figure 8 shows the change of 


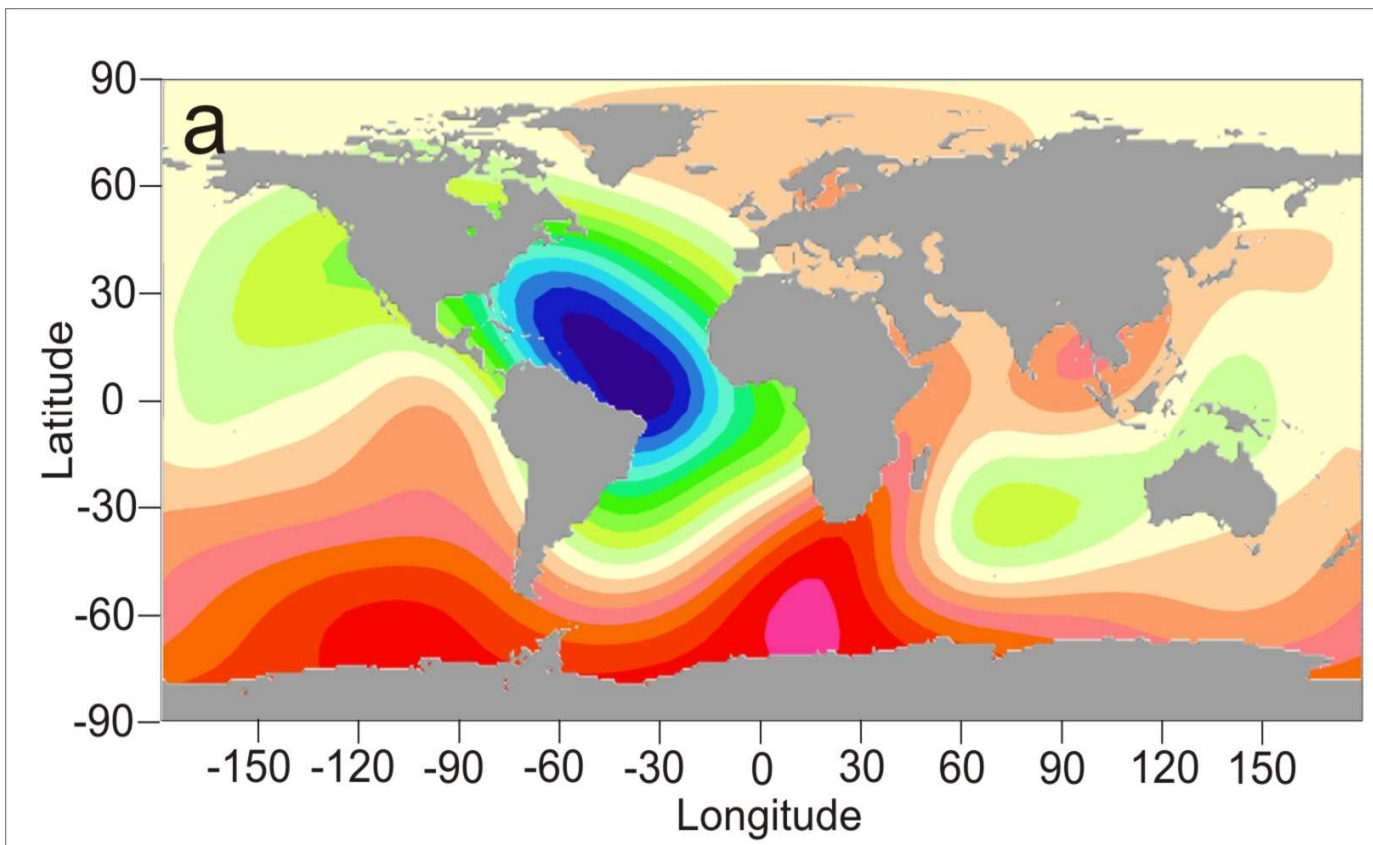

$\Delta \mathrm{B}(\mu \mathrm{T})$

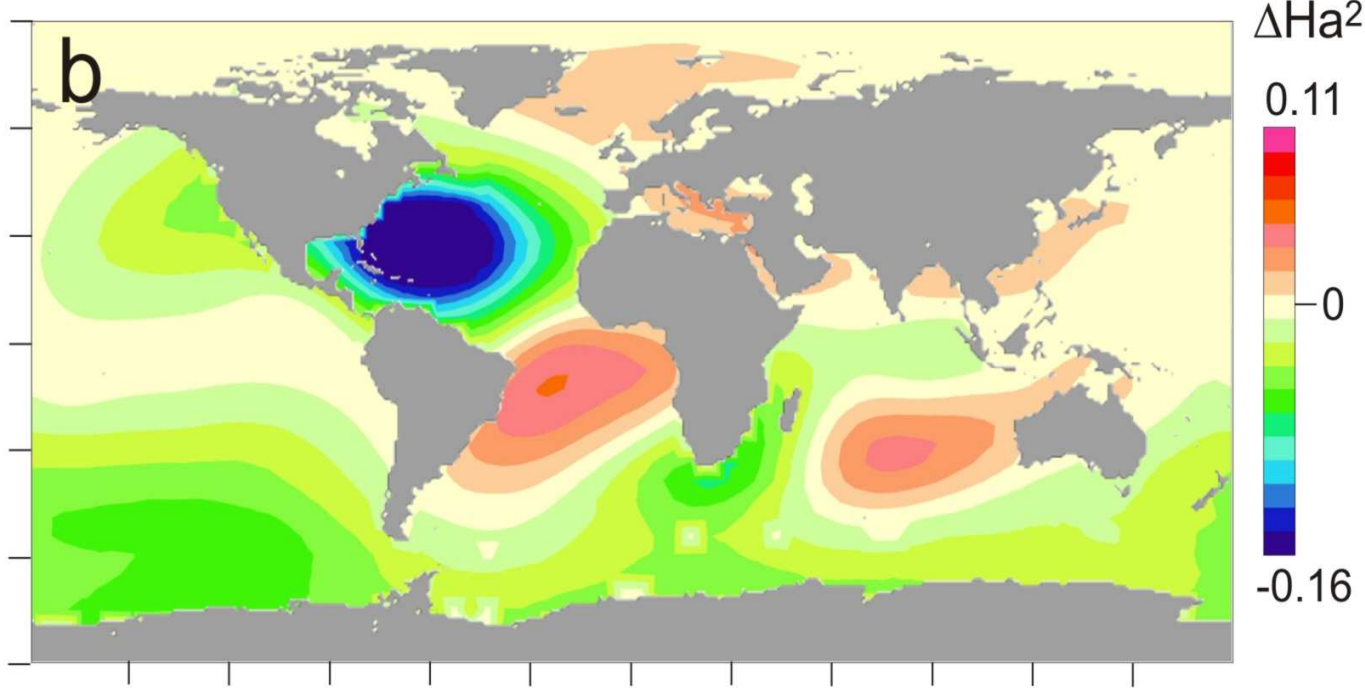

Figure 8. Global variation of the vertical geomagnetic component in the period of 1960-2000. (a) Change of the magnetic flux density, $\Delta B_{z}$. (b) Change of $H a^{2}$ obtained by the data of (a) for a water layer of $300 \mathrm{~m}$ thickness in upper thermocline (about 100-400 m depth). The worldwide predominant decrease of the absolute intensity of $B_{z}$ for this period becomes apparent because $H a^{2}$ relates to $\left|B_{z}\right|$ but is independent of its direction, which is governed by the respective hemisphere. In the green and blue shaded regions $\left(H a^{2}<0\right)$, the absolute value $\left|\Delta B_{z}\right|$ decreased in the period of 1960-2000, reddish colours indicate an increase (see colour bar scale on the right). At higher southern latitudes $\left|\Delta B_{z}\right|$ decreased exclusively. Geomagnetic data were obtained by the IGRF-11 (International Geomagnetic Reference Field) model (Finlay et al. 2010). Gridded data for electrical conductivity, density and viscosity in order to calculate $H a$ were obtained by processing $T$ and $S$ data from the World Ocean Atlas (Antonov et al. 2006; Locarnini et al. 2006) using the algorithms of Sharqawy et al. (2010).

the vertical geomagnetic component $\Delta B_{z}=B_{z}(2000)-B_{z}(1960)$. The change of $H a^{2}$ was calculated for a water layer with $300 \mathrm{~m}$ thickness in the upper ocean below the mixed layer. The average $|\Delta H a|^{2}=0.027$ approximately corresponds to $H a^{2}$ of the experiments $(0.030)$ at $B=60 \mathrm{mT}$. On condition that the findings described here apply for waters on large scales, e.g. with turnover times $\tau$ of 50 years and more for vertical remixing by convection, the recent geomagnetic secular variation could influence their heat content by $\sim 0.1 \%$ per century. This 
would correspond to a temperature change of $0.2-0.3 \mathrm{~K}$.

\section{Summary and conclusion}

The experiments show damping of convection by a MF is shown, whereby the changes of heat and mass flux seem to be satisfactorily correlated by the magnetic interaction parameter $N$ (Stuart number) as suggested earlier by theoretical investigations (Kenjeres and Hanjalic 2004, Ji and Gardner 1997). The measured MHD effect agrees well qualitatively with former experimental studies and theoretical considerations on MHD effects, using moderate electric fluid conductivities and magnetic fluxes. They cover small Hartmann numbers $(H a<0.5)$ which are expected in natural saltwaters by geomagnetism: a magnetic field brakes the flux of heat and mass by convection in an electrically conducting fluid $(\sigma>0)$ and the effect increases with the magnetic flux. Quantitatively, published results scatter by more than one order of magnitude. They are usually presented in the form of $\mathrm{Nu}=\mathrm{C}_{1} R a^{C_{2}} \mathrm{Ha}^{C_{3}}$, whereby the constants $C_{1}-C_{3}$ depend on so-called "regimes" or "domains"; ranges of $H a$, where convection patterns abruptly change, mainly at higher magnetic field strengths. The experimental results presented in the recent work show no discontinuous transitions and are similar to data of Cioni et al. (2000). The convection parameters were limited to $R a<10^{5}, H a<0.5$ and $N<0.01$. These borders given by the experimental system are relevant in any case to natural salt water flows in the geomagnetic field. Within these limits, the braking of heat convection is more or less linearly dependent on the square of magnetic flux and the turnover time of turbulent mixing in the fluid $\left(\equiv B^{2} \tau\right)$ for a given electric conductivity $\sigma$. This relation should allow the scaling of the small scale experimental results achieved here at comparably high magnetic fluxes,to oceanic conditions characterised by lower magnetic fluxes (Geo-MF), but longer equilibration times due to large volumes. A scaling up of the experiments to environmental conditions would roughly result in a randomly chosen water layer of $300 \mathrm{~m}$ thickness in the thermocline, for what a complete vertical remixing by convectional processes was estimated at 50-100 years. This is shorter than diffusion (>104 years) by orders of magnitude. Continuing this consideration: on a hypothetical twin earth lacking a Geo-MF, the heat- and momentum -fluxes into the deep sea would be $2-3 \%$ higher, shedding new light on reported coherences between global temperature and geomagnetic secular variations (Gallet et al. 2005, Courtillot et al. 2007). A detailed investigation of a possible influence of MHD effects by geomagnetism on the oceanic heat budget will be reserved to studies in progress, implementing suitable extensions in an established oceanic circulation model.

\section{Acknowledgements}

The author thanks H. Scheer (Munich, Germany) for his interest and for frequent discussions over many years, and R.J. Porra (Canberra) for help in preparing the manuscript.

Thank you to Prof. Dr. Susanne Renner for continuing support.

\section{References}

Andreev, O., Thess, A. and Haberstroh, C., Visualization of magnetoconvection. Phys. Fluids 2003, 15, 38863889.

Antonov, J.I., Locarnini, R.A., Boyer, T.P., Mishonov, A.V. and Garcia, H.E., World Ocean Atlas 2005. U.S. Government Printing Office, Washington, D.C. 2006.

Baranowski, B. and Kawczynski, A.L., Experimental determination of the critical rayleigh number in electrolyte solutions with concentration polarization. Electrochim. Acta 1972, 17, 699.

Broecker, W.S., The great ocean conveyor. Aip. Conf. Proc. 1992, 247, 129-161. 
Carton, J.A., Grodsky, S.A. and Liu, H., Variability of the oceanic mixed layer, 1960-2004. J. Clim. 2008, 21, 1029-1047.

Chaudhary, R.C. and Sharma, B. K., Combined heat and mass transfer by laminar mixed convection flow from a vertical surface with induced magnetic field. J. Appl. Phys. 2006, 99, DOI: 10.1063/1.2161817.

Cioni, S., Chaumat, S. and Sommeria, J., Effect of a vertical magnetic field on turbulent Rayleigh-Benard convection. Phys. Rev. E 2000, 62, R4520-R4523.

Courtillot,V., Gallet, Y., Le Mouel, J.-L., Fluteau, F. and Genevey, A., Are there connections between the Earth's magnetic field and climate? Earth Planet. Sci. Lett. 2007, 253 328-339.

De Luca, R., Lorentz force on sodium and chlorine ions in a salt water solution flow under a transverse magnetic field. Eur. J. Phys. 2009, 30, 459-466.

Finlay, C.C., Maus, S., Beggan, C.D., Bondar, T.N., Chambodut, A., Chernova, T.A., Chulliat, A., Golovkov, V.P., Hamilton, B., Hamoudi, M., Holme, R., Hulot, G., Kuang, W., Langlais, B., Lesur, V., Lowes, F.J., Luehr, H., Macmillan, S., Mandea, M., Mclean, S., Manoj, C., Menvielle, M., Michaelis, I., Olsen, N., Rauberg, J., Rother, M., Sabaka, T.J., Tangborn, A., Toffner-Clausen, L., Thebault, E., Thomson, A.W. P., Wardinski, I., Wei, Z. and Zvereva, T. I., International geomagnetic reference field: the eleventh generation. Geophys. J. Int. 2010, 183, 1216-1230.

Fofonoff, N.P., Physical-properties of seawater - a new salinity scale and equation of state for seawater. J. Geophys. Res. Ocean. 1985, 90, 3332-3342.

Gallet, Y., Genevey, A., and Fluteau, F., Does Earth's magnetic field secular variation control centennial climate change? Earth Planet. Sci. Lett. 2005, 236, 339-347.

Gat, J.R. and Shatkay, M., Gas exchange with saline waters. Limnol. Oceanogr. 1991, 36, 988-997.

Genin, L.G., Zhilin, V.G. and Manchkha, S.P., Effect of a longitudinal magnetic field on stability of flow of an electrically conducting liquid. High Temperature 1970, 8, 428.

Hanjalic, K. and Kenjeres, S., 't-Rans' Simulation of deterministic eddy structure in flows driven by thermal buoyancy and Lorentz force. Flow Turbul. Combust. 2001, 66, 427-451.

Henoch, C. and Stace, J., Experimental investigation of a salt water turbulent boundary layer modified by an applied streamwise magnetohydrodynamic body force. Phys. Fluids 1995, 7, 1371-1383.

Holman, J.P., Heat Transfer, 2009. (New York: McGraw-Hill).

Jackson, A., Jonkers, A.R.T. and Walker, M.R., Four centuries of geomagnetic secular variation from historical records. Phil. Trans. R. Soc. Lond.A 2000, 358, 957-990.

Janz, G.J. and Singer, S.K., Copenhagen standard sea water: Conductivity and salinity. J. Solution Chem. 1975, 4, 995-1003.

Ji, H.C. and Gardner, R.A., Numerical analysis of turbulent pipe flow in a transverse magnetic field. Int. J. Heat Mass Tran. 1997, 40, 1839-1851.

Karstensen, J. and Lorbacher, K., A practical indicator for surface ocean heat and freshwater buoyancy fluxes and its application to the Ncep Reanalysis data. Tellus A 2011, 63, 338-347.

Kazaryan, M.A., Shamanin, I.V., Lomov, I.V., Dolgopolov, S.Y., D'yachenko, A.N., Lobanov, A.N. and Murav'ev, E.N., Electrically and magnetically induced transfer of solvated ions in an isolated solution of salt in a polar dielectric. Theor. Found. Chem. Eng. 2010, 44, 58-66.

Kenjeres, S., Electromagnetic enhancement of turbulent heat transfer. Phys. Rev. E 2008, 78, DOI: 10.1103/PhysRevE.78.066309.

Kenjeres, S. and Hanjalic, K., On the implementation of effects of Lorentz force in turbulence closure models. Int. J. Heat Fluid Flow 2000, 21, 329-337.

Kenjeres, S. and Hanjalic, K., Numerical simulation of magnetic control of heat transfer in thermal convection. Int. J. Heat Fluid Flow 2004, 25, 559-568.

Locarnini, R.A., Mishonov, A.V., Antonov, J.I., Boyer, T.P. and Garcia, H.E., World Ocean Atlas 2005. U.S. Government Printing Office, Washington, D.C. 2006.

Lund, D.C., Lynch-Stieglitz, J. and Curry, W. B., Gulf Stream density structure and transport during the past millennium. Nature 2006, 444, 601-604.

Nadoor, S. and Bhattacharyya, S. P., Hydromagnetic thermal-convection between nonuniformly heated plates. Acta Mech. 1981, 41, 265-282.

Pazur, A. and Winklhofer, M., Magnetic effect on CO2 solubility in seawater: a possible link between geomagnetic field variations and climate. Geophys. Res. Let. 2008, 35, L16710.

Riedel L., Die Wärmeleitfähigkeit von wässrigen Lösungen starker Elektrolyte. Chem. Ing. Technik 1951, 23, $59-64$.

Sharqawy, M.H., Lienhard, J.H. and Zubair, S.M., Thermophysical properties of seawater: a review of existing correlations and data. Desal. Wat. Treat. 2010, 16, 354-380.

Shimomura, Y., Large eddy simulation of magnetohydrodynamic turbulent channel flows under a uniform magnetic-field. Phys. Fluids A 1991, 3, 3098-3106.

Sirevaag, A. and Fer, I., Vertical heat transfer in the Arctic Ocean: the role of double-diffusive mixing. J. Geophys. Res. Oceans 2012, 117(C7):7010-. DOI:10.1029/2012JC007910.

St Laurent, L. and Schmitt, R.W., The contribution of salt fingers to vertical mixing in the North Atlantic tracer release experiment. J. Phys. Oceanogr. 1999, 29, 1404-1424.

Stas'kov, N.I. and Ivashkevich, I.V., IR spectra of the optical constants of an industrial high-pressure polyethylene film. Opt. Spectrosc. 2008, 104, 846-850.

Stretch, D.D., Rottman, J.W., Venayagamoorthy, S.K., Nomura, K.K. and Rehmann, C.R., Mixing efficiency 
in decaying stably stratified turbulence. Dynam. Atmos. Oceans 2010, 49, 25-36.

Vialard, J. and Delecluse, P., An OGCM study for the TOGA decade. Part I: Role of salinity in the physics of the western Pacific fresh pool. J. Phys. Oceanogr. 1998, 28, 1071-1088.

Weast R.C., CRC Handbook of Chemistry and Physics, 1986 (Boca Raton, Florida: CRC Press). Weast R.C., CRC Handook of Chemistry and Physics, 1986 (Boca Raton, Florida: CRC Press).

\author{
(2)
}




\section{A.Pazur: Reduced heat transfer in saltwater by a magnetic field: do oceans have a "geomagnetic brake"?}

\section{Accompanying Material}

\section{Magnetic damping of turbulent flows}

The motion of an electrically-conducting fluid (i.e. sea-or salt-water) in a MF is described by the Navier-Stokes' momentum equations, the Maxwell's equations and by Ohm's law. These equations are connected by the Lorentz force term $\mathbf{F}_{\mathrm{L}}=\mathbf{J} \times \mathbf{B}$ where the current density, $\mathbf{J}$, is defined by Ohm's law as $\mathbf{J}=\sigma(-\nabla \phi+\mathbf{v} \times \mathbf{B})$. The set of equations describing the temperature and velocity field for our problem can be written as:

$$
\frac{\partial \mathbf{v}}{\partial t}=-(\mathbf{v} \cdot \nabla) \mathbf{v}+v \nabla^{2} \mathbf{v}-\frac{1}{\rho} \nabla p+\mathbf{F}_{B}+\mathbf{F}_{L}
$$

The terms on the right describe, in order, convection, diffusion (damping), pressure, the buoyant volume force, $\mathbf{F}_{B}$, (i.e. the buoyancy anomaly between two depths, $p_{1}, p_{2}$, of a water layer) and the (non-accelerating) Lorentz force, $\mathbf{F}_{L}$. The latter terms are defined as:

$$
\begin{aligned}
& \mathbf{F}_{B}=g \cdot\left(\beta\left(\left\langle T_{1}\right\rangle-\left\langle T_{2}\right\rangle\right)+\beta_{S}\left(\left\langle S_{1}\right\rangle-\left\langle S_{2}\right\rangle\right)\right) \\
& \mathbf{F}_{L}=\frac{\sigma(\Lambda)}{\rho(\Lambda)} \cdot\left(-\epsilon_{i j k}\left\langle B_{k}\right\rangle \frac{\partial\langle\phi\rangle}{\partial x_{j}}+\left\langle\mathrm{v}_{k}\right\rangle\left\langle B_{i}\right\rangle\left\langle B_{k}\right\rangle-\left\langle\mathrm{v}_{i}\right\rangle\left\langle B_{k}^{2}\right\rangle\right)
\end{aligned}
$$

Here the square brackets $\langle.$.$\rangle denote ensemble-averaged, time-dependent variables (i.e. volume$ related elements) and $\phi$ is the electric potential. Although $\mathbf{F}_{L}$ acts perpendicular to the MF direction, the largest reduction of heat transfer is obtained when the direction of the MF is aligned with the mean temperature gradient $\left(B_{k} \| z\right)$, that is, vertically (Chaudhary and Sharma, 2006), which is the buoyancy flux direction in the sea. On the turbulence subscale, the local temperature variance $\theta^{2} \cong k, \varepsilon$ will contribute preferentially in the main direction of the temperature gradient. For a 
constant MF in an electrically conducting fluid with negligible induction (as applies for sea water), the scalar volume force will reduce to $F_{L}=\mathrm{v}_{0} \sigma B^{2}$. The measure for the effective magnetic force in a fluid is expressed by the square of the dimensionless Hartmann number $\mathrm{Ha}^{2}$ (also known as Chandrasekhar number), which relates $F_{L}$ to the viscous (Stokes-) force $F_{S}$. The magnetic interaction parameter $N$ (Stuart number) is defined as the ratio of $H a^{2}$ and the Reynolds number, $R e$ :

$$
N=\frac{H a^{2}}{\operatorname{Re}}=\frac{F_{L}}{F_{S} \cdot \operatorname{Re}}=\frac{\sigma(\Lambda) \cdot B^{2} \cdot L_{0}}{\rho(\Lambda) \cdot \mathrm{v}} \quad \text { with } \quad H a=B \cdot l \cdot \sqrt{\frac{\sigma(\Lambda)}{\mu(\Lambda)}}
$$

Several attempts were made to find suitable magneto-hydrodynamic (MHD) parameters for turbulent fluid motion, which implies the extension of the classical $k$ - $\varepsilon$ model of turbulence by a magnetic friction term (Hanjalic and Kenjeres, 2002; Cioni et al., 2000). $N$ provides a time constant by $L_{0} / \mathrm{v}$; recent work links it directly to the dissipation time (Kenjeres and Hanjalic, 2000; Ji and Gardner, 1997), and agrees well with the relevant experimental results. The turbulent heat conductivity $\lambda_{t}$ results by the turbulent eddy viscosity $v_{t}$ and the turbulent Prandtl number $\operatorname{Pr}_{t}$ (usually $\sim 0.9$ ) after

$$
\begin{aligned}
& \lambda_{t}=\rho \cdot C \cdot \frac{v_{t}}{P r_{t}} \quad \text { with } \\
& v_{t}=\frac{\mu_{t}}{\rho}=C_{\mu} f_{\mu} \cdot \frac{k^{2}}{\varepsilon} \cdot \exp \left(-C_{1} N\right)
\end{aligned}
$$

using the damping constants $C_{\mu}, C_{l}$ which must be determined experimentally, and the standard damping function $f_{\mu}=1-0.3 \cdot \exp \left(-R_{t}{ }^{2}\right)$ with $R_{t}=\rho k^{2} / \varepsilon \mu$. The fluid momentum will be decreased by the MF as

$$
\rho \frac{\mathrm{d} \mathbf{v}}{\mathrm{d} t}=-\mathbf{v} \cdot \sigma(\Lambda) \cdot B^{2}
$$

The time course is governed by the magnetic breaking time $t_{m}=\rho / \sigma B^{2}(\mathrm{Ji}$ and Gardner, 1997), after which any thermal fluctuations should be arrested if the medium would have no energy exchange 
with its environment. In a natural (open) system, this results in an equilibration to a new steady state by an altered bulk heat flux. For large eddy times $t_{t}=L_{0} / u_{Z}$, the magnetic interaction parameter $N$ then becomes:

$$
N=\frac{t_{t}}{t_{m}}=\frac{\sigma(\Lambda) \cdot B^{2}}{\rho(\Lambda)} \cdot\left(\frac{k}{\varepsilon}\right)
$$

The initial velocity $u_{z, t=0}$ of the turbulent flow in (vertical) $z$-direction then will decrease in time $t$ by:

$$
u_{z}(t)=u_{z, t=0} \cdot \exp \left(-\frac{t}{t_{m}}\right)
$$

Earlier computational simulations (Hanjalic and Kenjeres, 2002) of vertical turbulence in an electrically conducting fluid show a behaviour in a MF that is very similar to the one seen in the experiments presented here by thermal imaging of the fluid surface. Without a MF, the vortex structures are randomly distributed and have a mushroom- or finger-like shape when viewed from above. A vertical MF corresponding to $H a=0.1$ causes predominantly ordered and cylindrical shaped vortices. $H a=0.1\left(H a^{2}=0.01\right)$ is, on average, reached in the open sea for $l_{0} \sim 60 \mathrm{~m}$ at midlatitudes $\left(B_{\mathrm{z}} \sim 30 \mu \mathrm{T}\right)$, and in our experiments at $\left(B_{\mathrm{z}}=60 \mathrm{mT}\right)$ for $l_{0}$ some $\mathrm{cm}$.

Effects of a small MF on the Lorentz force are inaccessible in experiments on a small volume over reasonably short periods. The field was, therefore, increased $\sim 1500$ fold above the mean geomagnetic flux. But the natural maritime environment, of course, provides small MF conditions and large water masses, which are structured in layers from tens to thousands of meters generally stratified in the thermocline below the mixed layer depth (MLD): years or even centuries are required for complete remixing by thermohaline convection processes. Such flow dynamics can be understood as the border case of large eddy turbulence to laminar flow with extreme dissipation times (Goldbaum et al., 1999). 
To estimate the influence of a MF on the heat content, $Q$, we assume the water-air surface heat exchange as a flat-plate stream with a Nusselt number $N u$, the heat transfer coefficient $\alpha_{s}$ and the heat flux $q_{s}:\left(L_{0}\right.$ unit length eg. $1 \mathrm{~m}, T_{S}$ water and $T_{A}$ air temperature):

$$
N u=C_{1} \cdot \operatorname{Re}^{C_{2}} \cdot \operatorname{Pr}^{C_{3}} \quad(10) \quad \alpha_{S}=N u \cdot \lambda / L_{0} \quad(11) \quad q_{S}=\alpha_{S} \cdot\left(T_{S}-T_{a}\right)
$$

$C_{1}, C_{2}, C_{3}$ are fluid mechanical constants, the values of $C_{1}=0.664, C_{2}=0.5, C_{3}=1 / 3$ were taken from (Holman, 2009). For the heat content change per volume, $\Delta Q\left[\mathrm{~J} / \mathrm{m}^{3}\right]$, during a time, $t$, we will obtain:

$$
\begin{aligned}
\Delta Q= & \frac{1}{h} \cdot \int_{t=0}^{\tau_{0}} 0.664 \cdot\left(\sqrt{\left(u(t)_{a, x}-u(t)_{s, x}\right)^{2}+\left(u(t)_{a, y}-u(t)_{s, y}\right)^{2}} \cdot \frac{L_{0}}{v_{a}}\right)^{0.5} \cdot \operatorname{Pr}_{a}{ }^{1 / 3} \\
& \cdot R(t) \cdot \alpha_{a} \cdot\left(T_{S}(t)-T_{a}(t)\right) \cdot\left(\exp ^{\left(-t / t_{m}(t)\right)}-\exp ^{\left(-t / t_{m}(t=0)\right)}\right) \cdot d t
\end{aligned}
$$

The first term in brackets is $R e$ with the resulting horizontal motion velocity of water $\left(u(t)_{s, x}, u(t)_{s, y}\right)$ against the wind $\left(u(t)_{a, x}, u(t)_{a, y}\right)$, where $x$ and $y$ define south-to-north and west-to-east, respectively, as positive directions. $R(t)$ is the relative increase of surface by the roughness of the sea $(R \geq 0)$. Viscosity $v_{a}$ and Prandtl number $P r_{a}$ relate to the air above the water, $h$ is the depth corresponding to $\tau_{0}$, the turbulence dissipation time ("large eddy" time) for this layer. This basic calculation by the maritime and meteorological quantities would require complete gridded climate data for the requested time span. When heat content data are available (Yu and Weller, 2007; Esbensen and Kushnir, 1981; Levitus et al., 2009), a more simple expression can be used by relating the magnetic interaction parameters $N$ :

$$
\Delta Q=Q \cdot\left(1-\exp \left(\frac{-t}{\tau_{0}}\right)\right) \cdot \ln \left(\frac{1+N\left[B_{\left.t=0 ; \tau_{0}\right]}\right.}{1+N\left[B(t) ; \tau_{0}\right]}\right)
$$


Here the left term yields the amount of redistribution of the initial heat content, $Q$, after the observation time $t$, whereas the right term gives the ratio of the old and new equilibrium after $\tau_{0}$, $B_{t=0}$ is the GEO-MF flux at the beginning and $B_{t}$ at the end of period $t$.

\section{Turbulence damping in the ocean by geomagnetism}

An attempt was made to extrapolate the experimental results to the open sea. The feasibility of such an extrapolation is supported by the fact, that the deficit of already transported heat and mass is determined by $N$ and $\tau_{0}$ in this way, that a large damping time compensates a small magnetic interaction parameter and vice versa. The examination of the fluid mechanical similarity of such different systems like the ocean and a laboratory setup is commonly done by comparing suitable dimensionless numbers, like already introduced here. The Nusselt number Nu represents the ratio of convective to conductive heat transport. Its long term average layes at 4.3 for the world ocean with higher values up to 20 in the tropical sea, if calculated by the heat transfer coefficient.

The magnetic friction forces in seawater caused by the geomagnetic field (GEO-MF) are weaker by nearly 6 orders compared to those in the published experiments, but $\tau_{0}$ in the sea, which crucially determines the mixing between distinct depths is appropriately larger. This will allow investigation of the magnetic damping in the marine environment by applying the $k / \varepsilon$ turbulence model. Presently, however, we will restrict this approach to heat and salt fluxes in the upper $300 \mathrm{~m}$, which is an accepted reference depth in oceanography (St Laurent and Schmitt, 1999, Palmer et al., 2007; Levitus et al., 2000) available nearly everywhere in the oceans beyond the continental shelves. The Hartmann number, $H a$ (eq. 5), for this layer approximates the value used in our experiments. For evaluating $(S, T, p)$ at a definite depth (pressure) $p$, we referenced the $T$ (temperature) and $S$ (salinity) data to the course of the thermocline which can be approximated by a negative exponential function; however, we used the more refined model of (Chan and Matthews, 
2005). Spatially resolved $T$ and $S$ data on longitude-latitude grids are available for discrete depth layers in the world ocean atlas (WOA) (Antonov et al., 2006; Locarnini et al., 2006). The mixed layer depth (MLD) was assumed by its general definitions of $T_{S S T^{-}} T_{M L D} \sim 0.8{ }^{\circ} \mathrm{C}$ and an annual or shorter period for complete mixing of waters (Kara et al., 2003; Yu and Weller, 2007). By averaging likewise gridded MLD data (using projection correction by latitudes) we obtained an annual world mean MLD of $61.4 \mathrm{~m}$ (table S1). The local buoyancy fluxes were determined by data from the WHOI “Objectively Analyzed air-sea Fluxes” (OAFlux) Project (Yu and Weller, 2007) and earlier products (Esbensen and Kushnir, 1981), heat content anomaly data were taken from the revised sets of (Levitus et al., 2009). Geomagnetic data sets completely covering the surface of the earth with sufficient accuracy are available since 1900 by the IGRF-11 (International Geomagnetic Reference Field) model (Finlay et al., 2010) and were used for a gridded reconstruction of the annual changes of vertical turbulence damping in the world ocean by the GEO-MF in the years 1960-2000. For calculations prior to 1900 , only world mean magnetic field data partially obtained from historical sources (Jackson et al., 2000) (also see Fig. S1) were available. The calculation applied here reproduces the change of oceanic heat content $\Delta Q$ by GEO-MF variations using the turbulence dissipation time $\tau_{0}$ on integral ("large eddy") scale in a given depth range. For practical use (eq. 14) can be used, where the left term expresses the amount of redistribution of the initial heat contents, $Q$, after the observation time $t$. The right term is the ratio of the old and new equilibrium after $\tau_{0}$ where $B_{t=0}$ is the GEO-MF flux at the beginning and $B_{t}$ at the end of period $t$. This first model of magnetic turbulence damping in the ocean is a simplification because it does not include horizontal mixing on smaller scales, in particular that near the surface, which are discussed otherwise (Dillon, 1982). The change of the average temperature in the given depth range can be directly obtained by $\Delta Q$. Such calculations indicate warming of about $0.4{ }^{\circ} \mathrm{C}$ over the period from 1800 to 2000 arising from the decrease (33 to $30 \mu \mathrm{T}$ ) of the GEO-MF mean vertical component (Finlay et al., 2010; Jackson et al., 2000), and a warming of $0.14{ }^{\circ} \mathrm{C}$ for the period from 1960 to 2000. 
The calculated contribution of magnetic turbulence damping to the evolution of bulk temperature is shown in Fig. S1.a (solid line) for the upper $300 \mathrm{~m}$ of the world oceans over the past two centuries. Geomagnetic data were used from (Jackson et al., 2000) and are depicted in the inserted diagram. The forward extrapolation to 2070 (dotted line) describes the hypothetical cooling scenario after reversing the GeoMF to its 1800 state: equilibrium would be re-established after the dissipation time (with a dissipation time constant of $\tau_{0}=57$ years (Fig.3.a). The relative changes of the total heat content, similarly calculated are summarized in Fig. S1.b for 18 selected locations (also see table S1) for the period (1900 to 2010), using magnetic data obtained by the IGRF-11 geomagnetic model. Large differences in the MF effect are observed, depending on the evolution of the local $\Delta B_{Z}$. The MF effect further reproduces qualitatively the lower rate of increase in global warming during the middle of the $20^{\text {th }}$ century (Brohan et al., 2006) which has been noted before (Pazur and Winklhofer, 2008). For any of the selected 18 sea locations, the relative heat changes predicted by the magnetic effect, $q_{r}$ ' are linearly correlated with the available data with a confidence level of 0.85: $q_{r}{ }^{\prime}=0.3664 \Delta Q_{r}+0.0402$, with $\Delta Q_{r}=\Delta Q / Q_{\text {total }}$ (Fig. S1.c).

Because climate has been accurately studied with extensive global coverage since 1960, this period was selected for an analysis by gridded data. Fig. S2.a shows the bulk heat content anomaly, $\Delta \mathrm{Q}$, for the world's oceans for the years 1960-2000 calculated by the data sources mentioned above (Levitus et al., 2009). The $5^{\circ}$ by $5^{\circ}$ grid was obtained by scaling down gridded data sets of higher resolution and running averages over 5 subsequent years each. The calculated bulk temperature anomalies, $\Delta \mathrm{T}$, for the upper $300 \mathrm{~m}$ are depicted on same grid scale in Fig. S2.b. They are based on the hypothesis discussed for magnetic damping in the $k / \varepsilon$ turbulence model, using the local vertical geomagnetic components, $\Delta B_{Z}$, as described above. Because of the relationship, $T_{a b s} \equiv Q_{t o t a l}$, identical symbols are used since bulk changes of $Q$ and $T$ are directly comparable. There are obvious coincidences in many regions (see Fig. S2.a and b). The largest change occurred, for 
example, in the mid-Atlantic Ocean (location no. 8 in table S1), where a large MF effect of $\Delta T \sim+0.37^{\circ} \mathrm{C}$ has also been calculated: it branches northward towards the Barents sea with a less warmed region in the Norwegian sea above Scotland. Also, the southern Atlantic, the southern Indic Ocean and the Philippine Sea show large, contiguous regions of warming; however, the equatorial Indian Ocean between Africa and Indonesia cooled by $\Delta T \sim-0.11^{\circ} \mathrm{C}$. Table $\mathrm{S} 1$, lists relevant data for 18 sea locations, sorted from north to south and selected for geographical and climatological reasons, as well the world average are listed together with their corresponding heat anomalies for 1960-2000. Negative and positive dissipation time constants in the $8^{\text {th }}$ column indicate an upward and downward directed bulk heat flux, respectively. Generally, warming results from downward heat fluxes in a decreasing Geo-MF $\left(\mathrm{Ha}_{1960}^{2}>\mathrm{Ha}^{2}{ }_{2000}\right)$ or upward heat fluxes in an increasing GeoMF. Otherwise regions with preferred downward flux (like location 13) show a heat loss, if the Geo-MF had increased. The correlation between the changes of heat content and the magnetic interaction parameter is evident in Fig. S2.c: in the world average the correlation coefficient is 0.75 , in some regions of the Atlantic it yet reaches 0.9. The solid black lines in the map mark the isomagnetic borders between regions with rising and falling GeoMF during 1960-2000, having a net zero change of $\mathrm{Ha}^{2}$ over this period. In these regions, the correlation is very low, because of large scattering in the absence of distinct trends.

\section{Summary and Conclusion}

In summary, the hypothesis for damping turbulence and, thereby, heat transport by a MF in seawater has been supported experimentally. The model can, furthermore, be extrapolated to oceanic heat budget data (Yu and Weller, 2007; Esbensen and Kushnir, 1981; Levitus et al., 2009). Changes of heat flux and environmental magnetism are satisfactorily correlated by the magnetic interaction parameter $N$ (Stuart number) as earlier suggested by theoretical considerations (Kenjeres and Hanjalic, 2004; Ji and Gardner, 1997). That magnetic friction decreases the convective heat 
transfer is also clearly demonstrated experimentally: this effect is related to the square of the Hartmann number, whereby the buoyancy flux is more or less anti-correlated to the Peclet number $P E$ (see Fig. S3 and S4). These findings also indicate a possible connection between climate and the state of the geomagnetic field, which has already been suggested in another context (Courtillot et al., 2007). He suggests an altered penetration of cosmic-rays in the atmosphere by changes of the GEO-MF: cosmic-rays are known to support the nucleation of clouds.

If the dissipation time of turbulent motion rises sufficiently in the large water volumes, $N$ becomes no longer negligible even for MF as weak as that of the earth. A local decrease of the absolute vertical geomagnetic field strength $\left|B_{Z}\right|$ facilitates vertical heat flux in both directions, thereby warming and cooling regions with downward- and upward-directed heat flux, respectively. The current model involves some simplifications: it is restricted to the upper $300 \mathrm{~m}$ of the ocean and neglects any feedback from heat and mass fluxes at the surface and at the "bottom" of the water layer. The flux gradients in the upper waters are averaged, which are seasonally opposite for the two hemispheres and mainly provide vertical mixing. But considering the results already obtained, this model should be expanded to the surface currents, the deep sea and to double-diffusive convection phenomena (Timmermans et al., 2003; Ruddick and Kerr, 2003; Ruddick and Richards, 2003). In general, the influence of the the geomagnetic field to the flow of seawater could be yet another factor contributing to the comprehension of oceanic heat anomalies, all above the prominent temperature trend of the middle and north Atlantic (Levitus et al., 2000; Levitus et al., 2009). Refinements of the model, including the horizontal bulk fluxes of heat, salt and mass, are required to obtain properly corrected heat transfer coefficients to the atmosphere. Although, beyond the scope of the present study, such work is anticipated in future investigations. 

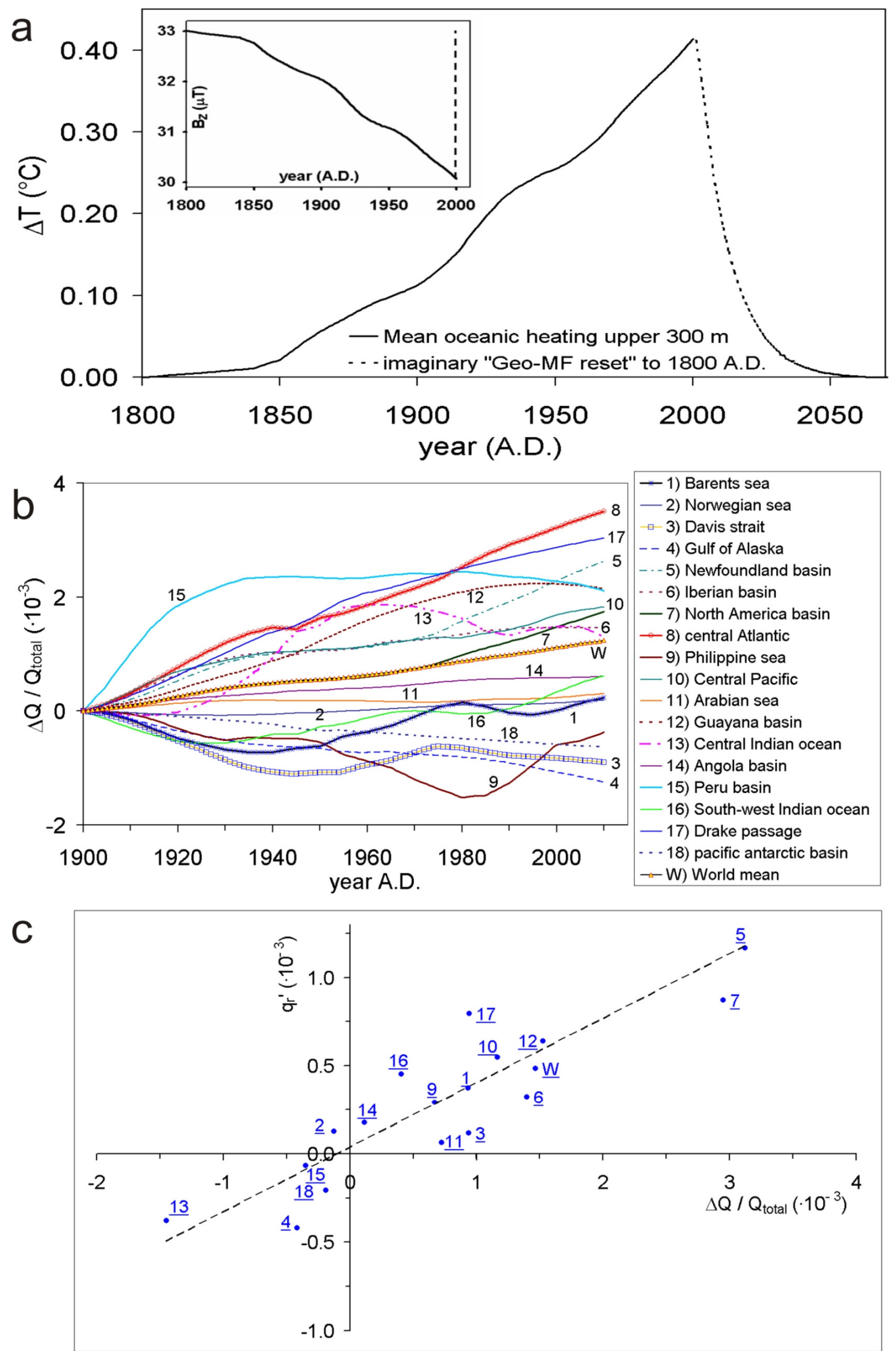
Fig. S1: Calculated heat anomalies for the world's oceans and 18 selected locations:

(a) Mean bulk temperature anomaly of the upper $300 \mathrm{~m}$ of the world oceans since 1800 modelled by magnetic turbulence damping (solid line). The inserted diagram shows the geomagnetic data used from (Jackson et al., 2000). The dotted line denotes the hypothetical results from "switching back" the GeoMF in 2000 to its state in 1800.

(b) Reconstruction of heat anomalies caused by magnetic turbulence damping for 18 locations in the sea, and the world mean value (W) (also see table 2, using the same numbers for the locations). Magnetic data were used from IGRF-11.

(c) Correlation between the changes of relative heat flux anomaly, $q_{r}$ ', and heat content for the 18 same locations. The coherence is well represented for regions, which became warmer (positive branch) or cooler (negative branch), having a correlation coefficient of 0.85 . 

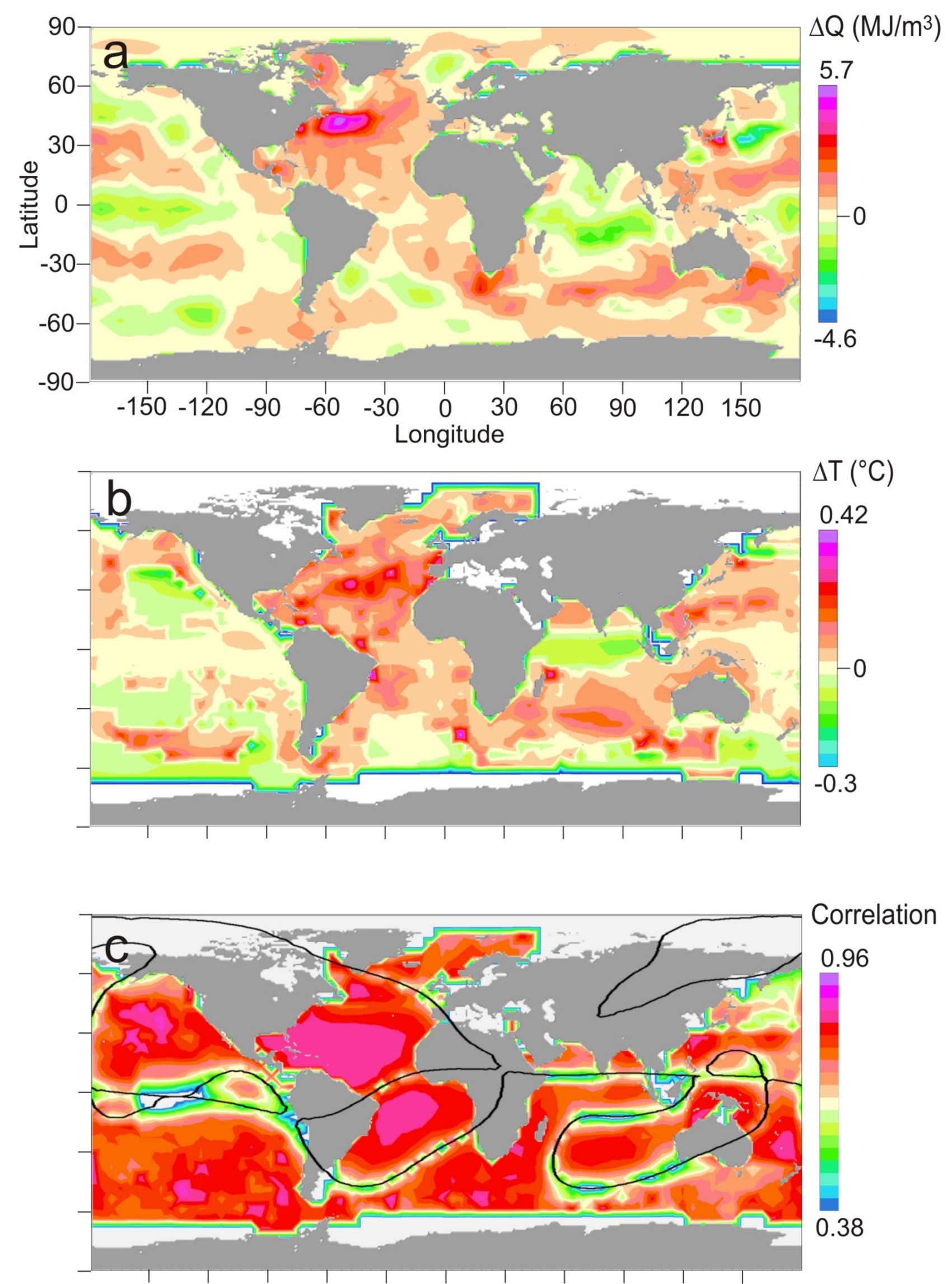
Fig. S2: Comparison of the observed and calculated oceanic heat anomalies:

(a) Heat content anomalies of the upper $300 \mathrm{~m}$ of the world's oceans for 1960-2000 (in $10^{6} \mathrm{~J} / \mathrm{m}^{3}$ ) reproduced on a $5^{\circ} \cdot 5^{\circ}$ grid after (Levitus et al., 2009).

(b) Calculated bulk temperature anomaly of the upper $300 \mathrm{~m}$ of the world oceans for 1960-2000 based on the magnetic turbulence damping model. Calculations use large eddy dissipation times $\left(\tau_{0}\right)$ and the changes of the vertical geomagnetic component $\left(\Delta B_{Z}\right)$ in this time span.

(c) Map of the correlation coefficient between the observed (a) and calculated (b) heat anomaly. The world mean correlation coefficient is 0.75 . It is higher in many regions, distinctly lower correlations follow the iso-magnetic borders between regions with rising and falling GeoMF (black solid lines).

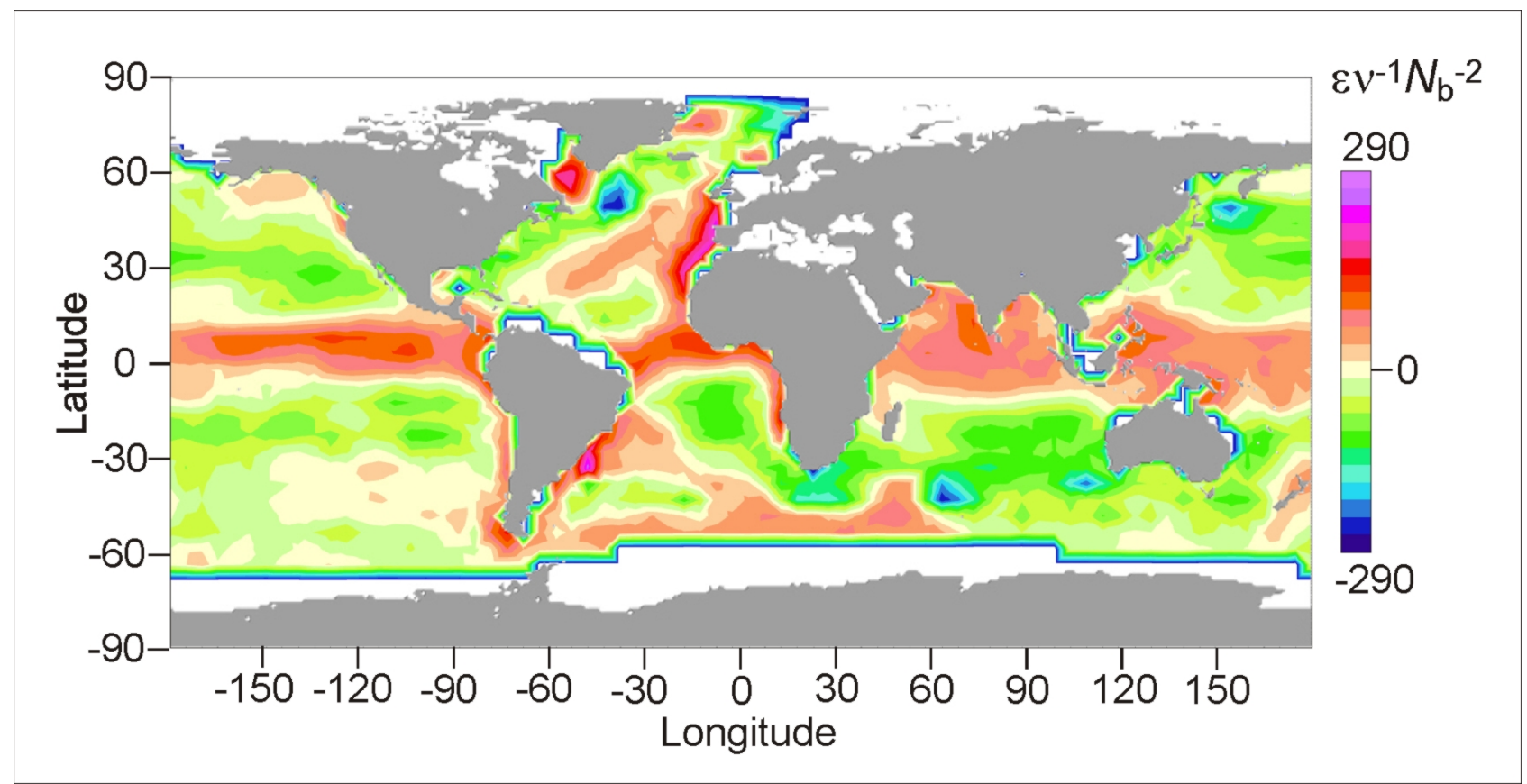


Fig. S3. Estimation of buoyancy (annual mean) in the upper $300 \mathrm{~m}$ of the oceans by the buoyancy Reynolds number, $\operatorname{Re}_{b}=\varepsilon v^{-1} N_{b}^{-2}$; it can be calculated by using the Brunt-Väisälä frequency $N_{b}$, see Appendix equation (B2.9). The sign of $R e_{b}$ indicates the prevalent direction of fluxes, downward being defined as positive. It competitively depends on the directions and total amounts of local heat and salt fluxes, as shown in (Karstensen and Lorbacher, 2011).

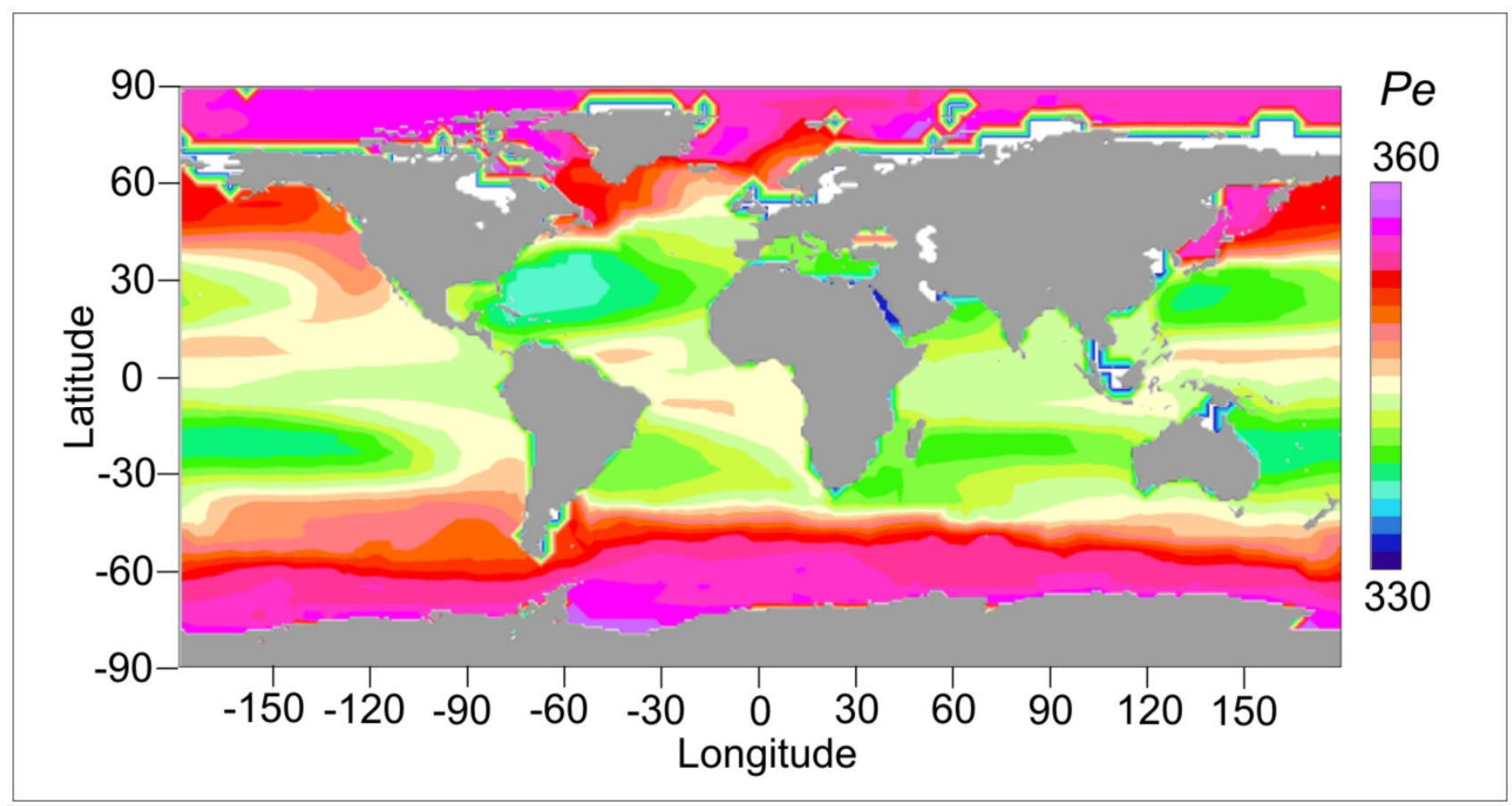

Fig. S4. The time integrated Peclet number $P e=h^{2} \cdot \rho \cdot C \cdot \lambda^{-1} \cdot \tau_{0}{ }^{-1}$ (see also main publication) in the upper thermocline $(h=300 \mathrm{~m})$ for $\tau_{0} \sim 57 \mathrm{a}$, which should approximately cover a complete remixing of this layer and should also be crudely representative for the timespan (1960-2000) of the discussed heat anomalies shown in table S1 and figure S2(a-b). Regions with an obvious increase of heat content like the middle Atlantic, which are hypothesized here to have an enhanced loss of vertical "magnetic braking" show lower Peclet numbers in this depth range. 
Table S1: Overview of the heat anomalies of 18 locations in the world's oceans and the world mean values (W) calculated, generally, by magnetic damping of turbulence in the upper $300 \mathrm{~m}$ for the period of 1960-2000. Oceanographic data were taken from the (WOA) (Antonov et al., 2006; Locarnini et al., 2006) and other relevant sources (Yu and Weller, 2007; Esbensen and Kushnir, 1981; Levitus et al., 2009). The geomagnetic reference was taken from the IGRF-11 model (Finlay et al., 2010). Dissipation times $k / \epsilon<0$ indicate an upward heat flux, giving the correct sign for total influx or loss of heat in the water column in order to obtain its bulk temperature anomaly.

\begin{tabular}{|c|c|c|c|c|c|c|c|c|c|c|c|c|c|}
\hline \multicolumn{4}{|c|}{ Geography } & \multicolumn{5}{|c|}{ Water column properties $(0-300 \mathrm{~m})$} & \multicolumn{3}{|c|}{ Geomagnetic data } & \multicolumn{2}{|c|}{ Magnetic effect } \\
\hline No & Sea location & $\begin{array}{c}\text { used } \\
\text { geographic } \\
\text { coordinate }\left[{ }^{\circ}\right]\end{array}$ & $\begin{array}{l}\text { Bathy- } \\
\text { metry } \\
{[\mathrm{m}]:}\end{array}$ & $\begin{array}{l}\text { MLD } \\
\text { annual } \\
\text { mean } \\
{[\mathrm{m}]:}\end{array}$ & $\begin{array}{c}\text { Average } \\
\text { Temp. } \\
{\left[{ }^{\circ} \mathrm{C}\right]}\end{array}$ & $\begin{array}{l}\text { Average } \\
\text { Salinity } \\
\text { PSU }\end{array}$ & $\begin{array}{c}\text { rel. Heat } \\
\text { Cont. } \\
\text { anomaly } \\
{\left[10^{-3} \text { of } 1\right]} \\
1960-2000\end{array}$ & $\begin{array}{c}\text { Dissi- } \\
\text { pation } \\
\text { time } k / \epsilon \\
{[a]^{1)}}\end{array}$ & $\begin{array}{c}\mathrm{B}_{1960} \\
{[\mu \mathrm{T}]} \\
\text { Vertical }\end{array}$ & $\begin{array}{c}\mathrm{B}_{2000} \\
{[\mu \mathrm{T}]} \\
\text { vertical }\end{array}$ & $\Delta H a^{2}$ & $\begin{array}{l}\text { rel. heatflux } \\
\text { anomaly } \\
{\left[q_{r}^{\prime} 10^{-3} \text { of }\right.} \\
1]^{2)}\end{array}$ & $\begin{array}{c}\text { Calculated } \\
\text { Temp. } \\
\text { anomaly } \\
{\left[{ }^{\circ} \mathrm{C}\right]}\end{array}$ \\
\hline 1 & Barents sea & $82.5 \mathrm{~N}, 27.5 \mathrm{E}$ & 3939 & 91.7 & 0.44 & 34.58 & 0.9351 & -71.2 & 54.59 & 55.12 & 0.0080 & 0.373 & 0.102 \\
\hline 2 & Norwegian sea & $70.5 \mathrm{~N}, 16.5 \mathrm{E}$ & 1614 & 209.6 & 4.90 & 35.08 & -0.124 & -16.4 & 51.30 & 52.02 & 0.0138 & 0.126 & 0.035 \\
\hline 3 & Davis strait & $66.5 \mathrm{~N}, 57.5 \mathrm{~W}$ & 959 & 50.1 & 2.00 & 33.89 & 1.34 & -47.0 & 55.49 & 55.73 & 0.0040 & 0.116 & 0.032 \\
\hline 4 & Gulf of Alaska & $52.5 \mathrm{~N}, 133.5 \mathrm{~W}$ & 2781 & 46.9 & 7.09 & 33.22 & -0.419 & -45.3 & 51.97 & 51.12 & -0.0177 & -0.421 & -0.118 \\
\hline 5 & Newfoundland basin & $42.5 \mathrm{~N}, 59.5 \mathrm{~W}$ & 2379 & 38.2 & 11.37 & 34.57 & 3.12 & 50.6 & 51.91 & 50.00 & -0.0510 & 1.166 & 0.332 \\
\hline 6 & Iberian basin & $40.5 \mathrm{~N}, 10.5 \mathrm{~W}$ & 3921 & 45.8 & 13.82 & 35.71 & 1.4 & 59.4 & 38.75 & 38.20 & -0.0128 & 0.323 & 0.093 \\
\hline 7 & North America basin & $37.5 \mathrm{~N}, 72.5 \mathrm{~W}$ & 2517 & 64.1 & 16.02 & 35.49 & 2.951 & 24.4 & 51.82 & 49.22 & -0.0886 & 0.871 & 0.252 \\
\hline 8 & central Atlantic & $37.5 \mathrm{~N}, 37.5 \mathrm{~W}$ & 3741 & 45.8 & 17.53 & 36.15 & 2.436 & 54.0 & 40.01 & 37.73 & -0.0653 & 1.364 & 0.376 \\
\hline 9 & Philippine sea & $25.5 \mathrm{~N}, 145.5 \mathrm{E}$ & 4598 & 32.2 & 20.31 & 34.78 & 0.67 & -51.4 & 24.18 & 24.96 & 0.0155 & 0.292 & 0.086 \\
\hline 10 & Central Pacific & $22.5 \mathrm{~N}, 159.5 \mathrm{~W}$ & 4864 & 53.0 & 19.00 & 34.73 & 1.165 & 97.6 & 23.12 & 22.25 & -0.0150 & 0.549 & 0.160 \\
\hline 11 & Arabian sea & $17.5 \mathrm{~N}, 70.5 \mathrm{E}$ & 2637 & 35.5 & 21.01 & 36.13 & 0.725 & -20.4 & 15.39 & 16.01 & 0.0085 & 0.062 & 0.018 \\
\hline 12 & Guyana basin & $0.5 \mathrm{~S}, 42.5 \mathrm{~W}$ & 2768 & 62.8 & 18.90 & 35.52 & 1.525 & 52.3 & 9.41 & 2.23 & -0.0323 & 0.639 & 0.187 \\
\hline 13 & $\begin{array}{l}\text { Central Indian } \\
\text { ocean }\end{array}$ & $7.5 \mathrm{~S}, 82.5 \mathrm{E}$ & 5342 & 34.8 & 19.58 & 34.84 & -1.45 & 30.1 & -37.95 & -39.07 & 0.0339 & -0.377 & -0.110 \\
\hline 14 & Angola basin & $9.5 \mathrm{~S}, 12.5 \mathrm{E}$ & 1963 & 6.4 & 18.28 & 35.37 & 0.117 & -24.3 & -19.83 & -21.07 & 0.0191 & 0.178 & 0.052 \\
\hline 15 & Peru basin & $17.5 \mathrm{~S}, 74.5 \mathrm{~W}$ & 4402 & 18.3 & 15.86 & 35.10 & -0.351 & -29.7 & -7.11 & -5.84 & -0.0055 & -0.066 & -0.019 \\
\hline 16 & $\begin{array}{l}\begin{array}{l}\text { South-west Indian } \\
\text { ocean }\end{array} \\
\end{array}$ & $32.5 \mathrm{~S}, 72.5 \mathrm{E}$ & 4512 & 49.1 & 16.31 & 35.46 & 0.405 & -37.8 & -37.95 & -39.07 & 0.0295 & 0.452 & 0.131 \\
\hline 17 & Drake passage & $62.5 \mathrm{~S}, 65.5 \mathrm{~W}$ & 3236 & 23.6 & 1.45 & 34.17 & 0.941 & 41.6 & -34.96 & -31.81 & -0.0311 & 0.796 & 0.219 \\
\hline 18 & $\begin{array}{l}\text { pacific Antarctic } \\
\text { basin }\end{array}$ & $62.5 \mathrm{~S}, 122.5 \mathrm{~W}$ & 4684 & 146.0 & 0.44 & 34.58 & -0.19 & -11.0 & -52.82 & -50.80 & -0.0293 & -0.207 & -0.057 \\
\hline $\mathrm{W}$ & World mean & ----- & 3795 & 61.4 & 11.13 & 34.87 & 1.464 & 57.0 & 31.19 & 30.03 & -0.0185 & 0.484 & 0.137 \\
\hline
\end{tabular}

1) Signs: "+" for downward, "“-" for upward heat flux

2) Signs: "+" downward heat flux and $\Delta H a^{2}<0$ or upward heat flux and $\Delta H a^{2}>0$, “-" upward heat flux and $\Delta H a^{2}<0$ or downward heat flux and $\Delta H a^{2}>0$. 


\section{Additional References}

Antonov, J. I., Locarnini, R. A., Boyer, T. P., Mishonov, A. V., and Garcia, H. E. 2006. World Ocean Atlas 2005. U.S. Government Printing Office, Washington, D.C.

Brohan, P., Kennedy, J. J., Harris, I., Tett, S. F. B., and Jones, P. D. 2006. Uncertainty Estimates in Regional and Global Observed Temperature Changes: a New Data Set From 1850. J Geophys. Res. Atmos. 111, DOI: 10.1029/2005JD006548.

Chan, V. and Matthews, R. A. 2005. Using the Generalized F Distribution to Model Limnetic Temperature Profile and Estimate Thermocline Depth. Ecol. Model. 188, 374-385.

Chaudhary, R. C. and Sharma, B. K. 2006. Combined Heat and Mass Transfer by Laminar Mixed Convection Flow From a Vertical Surface With Induced Magnetic Field. J. Appl. Phys. 99, DOI: 10.1063/1.2161817.

Cioni, S., Chaumat, S., and Sommeria, J. 2000. Effect of a Vertical Magnetic Field on Turbulent Rayleigh-Benard Convection. Phys. Rev. E 62, R4520-R4523.

Courtillot, V., Gallet, Y., Le Mouel, J.-L., Fluteau, F., and Genevey, A. 2007. Are there connections between the Earth's magnetic field and climate? Earth Planet. Sci. Lett. 253, 328-339.

Dillon, T. M. 1982. Vertical Overturns - a Comparison of Thorpe and Ozmidov Length Scales. $J$. Geophys. Res. Ocean 87, 9601-9613.

Esbensen, S. K. and Kushnir Y. 1981. The Heat Budget of the Global Ocean: An Atlas Based on Estimates from Surface Marine Observations. Report No. 29. Climate Research Institute, Oregon State University, Oregon State University.

Finlay, C. C., Maus, S., Beggan, C. D., Bondar, T. N., Chambodut, A., Chernova, T. A., Chulliat, A., Golovkov, V. P., Hamilton, B., Hamoudi, M., Holme, R., Hulot, G., Kuang, W., Langlais, B., Lesur, V., Lowes, F. J., Luehr, H., Macmillan, S., Mandea, M., Mclean, S., Manoj, C., Menvielle, M., Michaelis, I., Olsen, N., Rauberg, J., Rother, M., Sabaka, T. J., Tangborn, A., Toffner-Clausen, 
L., Thebault, E., Thomson, A. W. P., Wardinski, I., Wei, Z., and Zvereva, T. I. 2010. International Geomagnetic Reference Field: the Eleventh Generation. Geophys. J. Int. 183, 1216-1230.

Goldbaum, B., Branover, H., and Moiseev, S. S. 1999. Turbulence in the Wake and Long-Living Vortex Structures. Phys. Chem. Earth PT B 24, 623-626.

Hanjalic, K. and Kenjeres, S. 2002. Simulation and Identification of Deterministic Structures in Thermal and Magnetic Convection. Ann. N.Y. Acad. Sci. 972, 19-28.

Holman, J. P. 2009. Heat Transfer. McGraw-Hill, New York.

Jackson, A., Jonkers, A. R. T., and Walker, M. R. 2000. Four centuries of geomagnetic secular variation from historical records. Phil. Trans. R. Soc. Lond. A 358, 957.990.

Ji, H. C. and Gardner, R. A. 1997. Numerical Analysis of Turbulent Pipe Flow in a Transverse Magnetic Field. Int. J. Heat Mass Tran. 40, 1839-1851.

Kara, A. B., Rochford, P. A., and Hurlburt, H. E. 2003. Mixed Layer Depth Variability Over the Global Ocean. J. Geophys. Res. Ocean 108, DOI: 10.1029/2000JC000736.

Karstensen, J. and Lorbacher, K. 2011. A Practical Indicator for Surface Ocean Heat and Freshwater Buoyancy Fluxes and Its Application to the Ncep Reanalysis Data. Tellus A 63, 338347.

Kenjeres, S. and Hanjalic, K. 2000. On the Implementation of Effects of Lorentz Force in Turbulence Closure Models. Int. J. Heat Fluid Fl. 21, 329-337.

Kenjeres, S. and Hanjalic, K. 2004. Numerical Simulation of Magnetic Control of Heat Transfer in Thermal Convection. Int. J. Heat Fluid Flow 25, 559-568.

Levitus, S., Antonov, J. I., Boyer, T. P., Locarnini, R. A., Garcia, H. E., and Mishonov, A. V. 2009. Global Ocean Heat Content 1955-2008 in Light of Recently Revealed Instrumentation Problems. Geophys. Res. Let. 36, L07608. 
Levitus, S., Antonov, J. I., Boyer, T. P., and Stephens, C. 2000. Warming of the World Ocean. Science 287, 2225-2229.

Locarnini, R. A., Mishonov, A. V., Antonov, J. I., Boyer, T. P., and Garcia, H. E. 2006. World Ocean Atlas 2005. U.S. Government Printing Office, Washington, D.C.

Palmer, M. D., Haines, K., Tett, S. F. B., and Ansell, T. J. 2007. Isolating the Signal of Ocean Global Warming. Geophys. Res. Let. 34, L23610.

Pazur, A. and Winklhofer, M. 2008. Magnetic effect on CO2 solubility in seawater: a possible link between geomagnetic field variations and climate. Geophys. Res. Let. 35, L16710.

Ruddick, B. and Kerr, O. 2003. Oceanic Thermohaline Intrusions: Theory. Prog. Oceanogr. 56, 483-497.

Ruddick, B. and Richards, K. 2003. Oceanic Thermohaline Intrusions: Observations. Prog. Oceanogr. 56, 499-527.

St Laurent, L. and Schmitt, R. W. 1999. The Contribution of Salt Fingers to Vertical Mixing in the North Atlantic Tracer Release Experiment. J. Phys. Oceanogr. 29, 1404-1424.

Timmermans, M.-L., Garrett, C., and Carmack, E. 2003. The thermohaline structure and evolution of the deep waters in the Canada Basin, Arctic Ocean. Deep Sea Res. 50, 1305-1321.

Yu, L. and Weller, R. A. 2007. Objectively Analyzed Air-Sea Heat Fluxes for the Global Ice-Free Oceans (1981-2005). Bull. Am. Meteorol. Soc. 88, 527-539. 